\title{
Arabidopsis Lectin Receptor Kinases LecRK-IX.1 and LecRK-IX.2 Are Functional Analogs in Regulating Phytophthora Resistance and Plant Cell Death
}

\author{
Yan Wang, ${ }^{1}$ Jan H. G. Cordewener, ${ }^{2}$ Antoine H. P. America, ${ }^{2}$ Weixing Shan, ${ }^{3}$ Klaas Bouwmeester,,${ }^{1,4}$ \\ and Francine Govers ${ }^{1}$ \\ ${ }^{1}$ Laboratory of Phytopathology, Plant Sciences Group, Wageningen University, Wageningen, The Netherlands; ${ }^{2}$ Plant Research \\ International, Wageningen University; ${ }^{3}$ State Key Laboratory of Crop Stress Biology for Arid Areas, Northwest A\&F University, \\ Yangling, P. R. China; ${ }^{4}$ Plant-Microbe Interactions, Department of Biology, Faculty of Science, Utrecht University, Utrecht, The \\ Netherlands
}

Submitted 30 April 2015. Accepted 16 May 2015.

L-type lectin receptor kinases (LecRK) are potential immune receptors. Here, we characterized two closely-related Arabidopsis LecRK, LecRK-IX.1 and LecRK-IX.2, of which T-DNA insertion mutants showed compromised resistance to Phytophthora brassicae and Phytophthora capsici, with double mutants showing additive susceptibility. Overexpression of LecRK-IX.1 or LecRK-IX.2 in Arabidopsis and transient expression in Nicotiana benthamiana increased Phytophthora resistance but also induced cell death. Phytophthora resistance required both the lectin domain and kinase activity, but for cell death, the lectin domain was not needed. Silencing of the two closely related mitogen-activated protein kinase genes $N b S I P K$ and $N b N T F 4$ in $N$. benthamiana completely abolished LecRK-IX.1-induced cell death but not Phytophthora resistance. Liquid chromatography-mass spectrometry analysis of protein complexes coimmunoprecipitated in planta with LecRKIX.1 or LecRK-IX.2 as bait, resulted in the identification of the $N$. benthamiana ABC transporter NbPDR1 as a potential interactor of both LecRK. The closest homolog of NbPDR1 in Arabidopsis is ABCG40, and coimmunoprecipitation experiments showed that ABCG40 associates with LecRK-IX.1 and LecRKIX.2 in planta. Similar to the LecRK mutants, ABCG40 mutants showed compromised Phytophthora resistance. This study shows that LecRK-IX.1 and LecRK-IX.2 are Phytophthora resistance components that function independent of each other and independent of the cell-death phenotype. They both interact with the same $\mathrm{ABC}$ transporter, suggesting that they exploit similar signal transduction pathways.

Plants are constantly threatened by microbes and have evolved strategies to detect microbial infection via various cell surface and intracellular receptors (Spoel and Dong 2012). Defense responses initiated by pathogen perception through cell surface pattern recognition receptors (PRR) provide the first line of innate

Klaas Bouwmeester and Francine Govers contributed equally to the article.

Corresponding author: F. Govers; Telephone: +31 317 483138; E-mail: Francine.Govers@wur.nl

*The $\boldsymbol{e}$-Xtra logo stands for "electronic extra" and indicates that seven supplementary figures and three supplementary tables are published online.

(c) 2015 The American Phytopathological Society immunity and collectively suppress the majority of invading microbes (Boller and Felix 2009). PRR rapidly form complexes via association with other components to initiate signal transduction cascades upon recognition of conserved microbial molecules, the so-called microbe-associated molecular patterns (MAMPs) or endogenous elicitors released from plants, known as damageassociated molecular patterns (DAMPs) (Liebrand et al. 2014; Macho and Zipfel 2014; Sun et al. 2013; Zhang and Zhou 2010). As a result, various cellular responses are initiated, including production of reactive oxygen species (ROS), activation of mitogen-activated protein kinase (MAPK) cascades, secretion of antimicrobial compounds, and induction of defense-related gene expression (Boller and Felix 2009). In some cases, activation of cell-surface receptors also leads to plant cell death (Gao et al. 2009).

Plant genomes encode a large number of cell surface receptors with an intracellular kinase domain. These so-called receptorlike kinases (RLK) not only act as PRR to perceive pathogens but also can function as signaling partners participating in PRRmediated downstream signaling (Chinchilla et al. 2009; Liebrand et al. 2014). RLK are classified based on their versatile extracellular domains, which are thought to determine ligand perception (Shiu and Bleecker 2001). L-type lectin receptor kinases (LecRK) are a group of RLK with an extracellular legume-like lectin domain (Bouwmeester and Govers 2009; Hervé et al. 1999). Previously, we found that one of the LecRK in Arabidopsis, i.e., LecRK-I.9, plays a crucial role in resistance to Phytophthora brassicae and acts as a mediator of plant cell wall-plasma membrane adhesion (Bouwmeester et al. 2011). More recently, the same LecRK was identified as the first plant receptor for extracellular ATP (eATP) and was found to be required for eATP-mediated downstream signaling (Choi et al. 2014). LecRK-I.9 is a member of a family consisting of 45 LecRK in Arabidopsis. Based on sequence similarity and phylogeny, these LecRK were divided into nine clades (clade I to clade IX) and seven singletons (Bouwmeester and Govers 2009). In recent years, several Arabidopsis LecRK other than LecRK-I.9 have been found to be implicated in plant immunity (Vaid et al. 2013). For example, LecRK-VI.2, which is required for priming $\beta$-aminobutyric acid-induced resistance, associates with the flagellin receptor FLS2 and positively regulates MAMP-mediated plant defense (Huang et al. 2014; Singh et al. 2012). LecRK-V.5 was found to play a dual role in plant resistance against different pathogens. It negatively regulates plant stomatal immunity against bacterial pathogens but positively contributes to Phytophthora 
resistance (Desclos-Theveniau et al. 2012; Wang et al. 2014). A systematic screen of Arabidopsis LecRK T-DNA insertion lines identified several additional LecRK that are involved in resistance against either Alternaria brassicicola or Phytophthora or Pseudomonas pathogens (Wang et al. 2014). Among these are LecRKIX.1 (At5g10530) and LecRK-IX.2 (At5g65600), the only two members in clade IX (Bouwmeester and Govers 2009).

In this study, we performed more detailed analyses on the role of Arabidopsis LecRK-IX.1 and LecRK-IX.2 in Phytophthora resistance. We compared the susceptibility of the null mutants lecrk-IX.1 and lecrk-IX.2 with double mutants and generated overexpression lines to confirm the role of LecRK-IX.1 and LecRK-IX.2 in Phytophthora resistance. Subsequently, we assayed the response of transgenic Arabidopsis plants expressing mutated versions of the two LecRK and pinpointed the domains required for resistance and cell-death responses. In addition, we transiently expressed the two LecRK in the solanaceous plant Nicotiana benthamiana, to monitor induced plant responses. Finally, by means of in planta coimmunoprecipitation and liquid chromatography-mass spectrometry (LC-MS), we identified a protein interacting with LecRK-IX.1 and LecRK-IX.2 that seems to be required for Phytophthora resistance.

\section{RESULTS}

\section{Arabidopsis mutants lecrk-IX.1 and lecrk-IX.2 show compromised Phytophthora resistance.}

Previously, LecRK-IX.1 and LecRK-IX.2 were identified as potential resistance components based on the finding that the Arabidopsis mutants lecrk-IX.1 and lecrk-IX.2 showed gain of susceptibility to the nonadapted isolates $P$. brassicae $\mathrm{HH}$ and $P$. capsici LT123. In contrast, the response to the fungal pathogen Alternaria brassicicola MUCL20297 or the bacterial pathogen Pseudomonas syringae DC3000 was not changed in these mutants (Wang et al. 2014) (Supplementary Fig. 1). In Arabidopsis, secondary metabolites, such as salicylic acid, jasmonic acid, ethylene, camalexin, and indole glucosinolates, have been found to be required for resistance to Phytophthora pathogens (Attard et al. 2010; Schlaeppi et al. 2010; Wang et al. 2013a). Expression of marker genes indicative for the related pathways was found to be induced upon inoculation with $P$. brassicae or $P$. capsici (Roetschi et al. 2001; Schlaeppi et al. 2010; Wang et al. 2013b). To determine whether these pathways are involved in resistance mediated by LecRK-IX.1 and LecRK-IX.2, we compared the expression levels of these marker genes in lecrk-IX.1, lecrk-IX.2, and Col-0 during infection by $P$. capsici LT123. As shown in Figure 1A, induction of all selected marker genes is less pronounced in lecrk-IX.I and lecrk-IX.2 as compared with Col-0, in particular for $P R I$, a salicylic acid marker gene, and $C Y P 71 B 15$, which is required for camalexin biosynthesis. Compared with lecrk-IX.1, overall lower expression levels of $P R 1$ and $C Y P 71 B 15$ were found in lecrk-IX.2. In addition, $P D F 1.2$, a jasmonic acid/ethylene marker gene also showed a lower expression in lecrk-IX.2, whereas the expression of $C Y P 81 F 2$, a marker gene for indole glucosinolate biosynthesis was comparable in the two mutants.

To determine whether LecRK-IX.1 and LecRK-IX.2 are functionally redundant, two independent homozygous double mutants, termed lecrk-IX.1/2 and lecrk-IX.2/1, were generated with T-DNA insertions in both LecRK-IX. 1 and LecRK-IX.2 (Fig. 1B). The lack of expression of both LecRK was confirmed in the double mutants (Fig. 1C). Compared with Col-0 and the parental null mutants, the double mutants showed no visible growth alterations or developmental defects. Upon inoculation with $P$. capsici LT123, the double mutants showed increased susceptibility compared with the single mutants (Fig. 1D), and this was confirmed by the increased biomass of $P$. capsici in infected leaves (Fig. 1E). In addition, the double mutants also showed slightly enhanced susceptibility upon inoculation with $P$. brassicae. These results indicate that LecRK-IX.1 and LecRK-IX.2 function synergistically in conferring Phytophthora resistance.

\section{Overexpression of LecRK-IX.1 or LecRK-IX.2 \\ in Arabidopsis induces cell death and Phytophthora resistance.}

To further confirm the role of LecRK-IX.1 and LecRK-IX.2 in Phytophthora resistance, we generated Arabidopsis transgenic lines expressing LecRK-IX.1 or LecRK-IX.2 under control of the Cauliflower mosaic virus 35S promoter, named 35S-IX.1 and $35 S-I X .2$, respectively (Fig. 2). During the first 2 weeks of growth, the 35S-IX.1 and 35S-IX.2 lines were morphologically indistinguishable from the recipient Col- 0 plants or Col- 0 transformed with a green fluorescent protein construct $(35 S-G F P)$. Thereafter, part of the 35S-IX.1 and 35S-IX.2 lines displayed spontaneous necrosis and retarded growth in comparison with Col-0 or 35S-GFP (Fig. 2B). When examined under the microscope, these plants showed intensive staining with trypan blue, indicative of cell death (Fig. 2B). When transgene expression levels were monitored by quantitative reverse transcriptionpolymerase chain reaction (qRT-PCR), it appeared that transgenic lines with a cell-death phenotype showed higher transgene expression levels than those without (Fig. 2C). Apparently, the induced cell death correlates with transgene expression levels.

To determine whether overexpression of LecRK-IX.1 or LecRKIX.2 increases Arabidopsis resistance to Phytophthora pathogens, transgenic lines with a similar growth phenotype as Col-0 plants, i.e., showing neither macroscopically nor microscopically visible cell death, were selected for infection assays with $P$. capsici LT263. Col-0 and 35S-GFP lines developed severe disease symptoms 3 days postinoculation (dpi). In comparison, the $35 S-I X .1$ and $35 S-I X .2$ lines showed less severe disease symptoms and less P. capsici biomass (Fig. 3A and D; Supplementary Fig. 2). These lines also showed less severe disease symptoms when inoculated with $P$. brassicae CBS686.95 (Supplementary Fig. 3), demonstrating that expression of LecRK-IX.1 and LecRK-IX.2 can inhibit infection by different Phytophthora species. Cell death is an important component of plant resistance and is often observed in incompatible Phytophthora-Arabidopsis interactions (Huitema et al. 2003; Roetschi et al. 2001; Wang et al. 2013a). To determine whether overexpression of LecRK-IX.1 and LecRK-IX.2 causes increased plant cell death upon infection, inoculated leaves were stained with trypan blue and were investigated by microscopy. Upon $P$. capsici penetration, hardly any cell death was observed, neither in 35S-IX.1-1 and 35S-IX.2-1 leaves nor in the control leaves from Col-0 and 35S-GFP plants (Fig. 3B). Formation of papillae, though, was increased at the penetration sites in leaves of $35 S-I X .1-1$ or $35 S-I X .2-1$ when compared with Col-0 or $35 S$ GFP leaves (Fig. 3B). Collectively, these results indicate that both LecRK-IX. 1 and LecRK-IX.2 function in plant cell-death induction and resistance to $P$. brassicae and $P$. capsici. The induced cell death, however, is not a prerequisite for Phytophthora resistance.

\section{Contribution of the lectin domain and kinase activity to LecRK-mediated cell death and Phytophthora resistance in Arabidopsis.}

The extracellular domains and a functional kinase domain have been shown to be essential for the biological function of several RLK (Gómez-Gómez et al. 2001; Schwessinger and Ronald 2012). Hence, we investigated whether both domains are required for LecRK-IX.1 and LecRK-IX.2 to mediate plant cell death and Phytophthora resistance. Truncated constructs lacking the lectin domain (i.e., LecRK-IX.1- $\Delta$ lectin and LecRKIX.2- $\Delta$ lectin) were generated and transformed to Col-0 (Fig. 2A). Similar to $35 S-I X .1$ and $35 S-I X .2$ lines, plants expressing either 


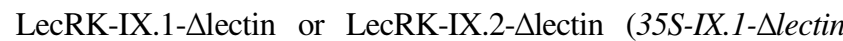
and 35S-IX.2-Alectin lines, respectively) varied in cell-death phenotype (Fig. 2B). Transgenic lines with relatively high transgene expression levels showed cell death (Fig. 2B and C). To assess the importance of the kinase domain, kinase-dead mutants were generated by substitution of the essential RD residues in the catalytic loop to RN or AA (Fig. 2A). In the transgenic lines (35S-IX.1-RN/AA and 35S-IX.2-RN/AA, respectively) different transgene expression levels were detected (Fig. 2C), but none of these lines displayed cell death or any other apparent phenotypic change when compared with Col-0 (Fig. 2B and C). Overall, these results indicate that the cell-death phenotype triggered by overexpression of LecRK-IX.1 or LecRK-IX.2 is dependent on the kinase activity but not on the lectin domain.

Infection assays with $P$. capsici LT263 were performed on transgenic lines that are morphologically undistinguishable from Col-0. The transgenic lines expressing kinase-dead LecRK mutants showed similar disease symptoms as Col-0 or 35S-GFP (Fig. 3C). Similar susceptibility was also observed on the transgenic lines expressing the lectin-deletion mutants (Fig. 3C). In
A

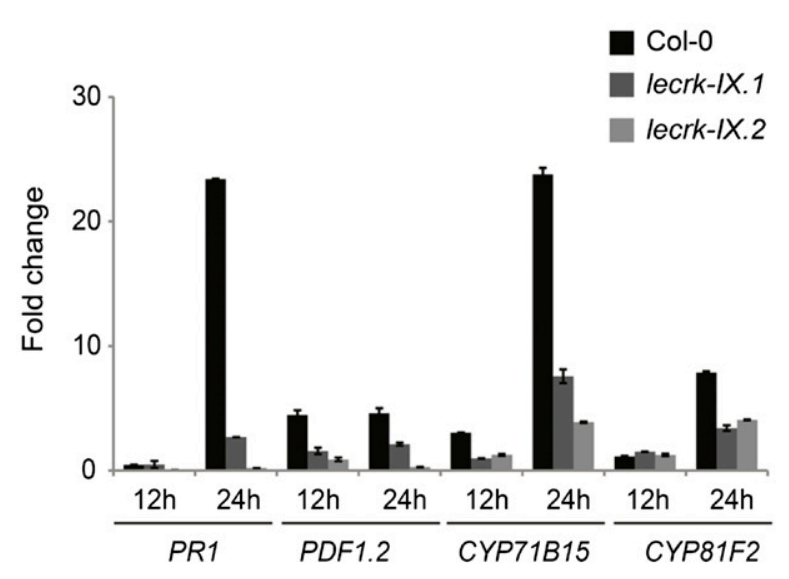

D

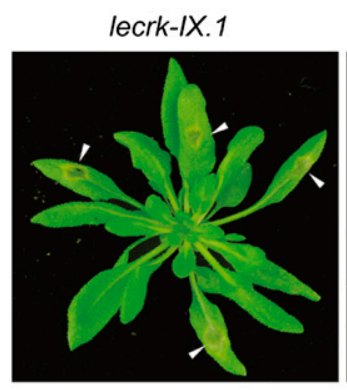

Col-0

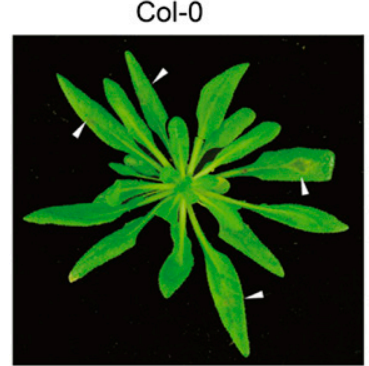

lecrk-IX.2

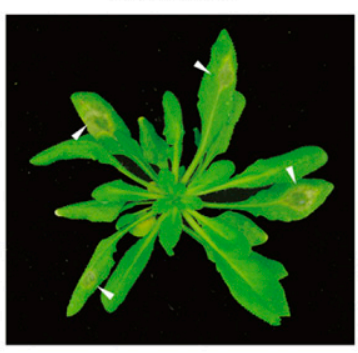

lecrk-IX.1/2

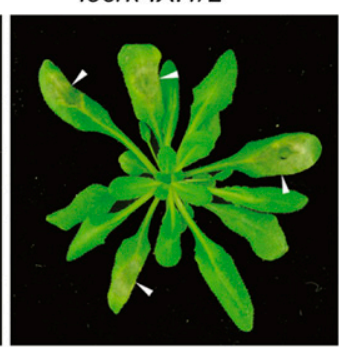

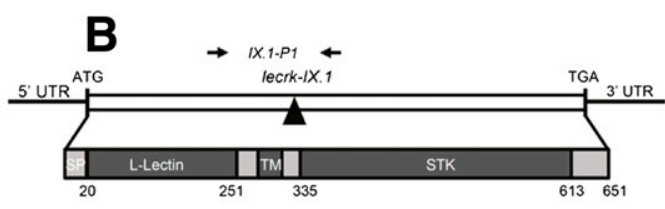
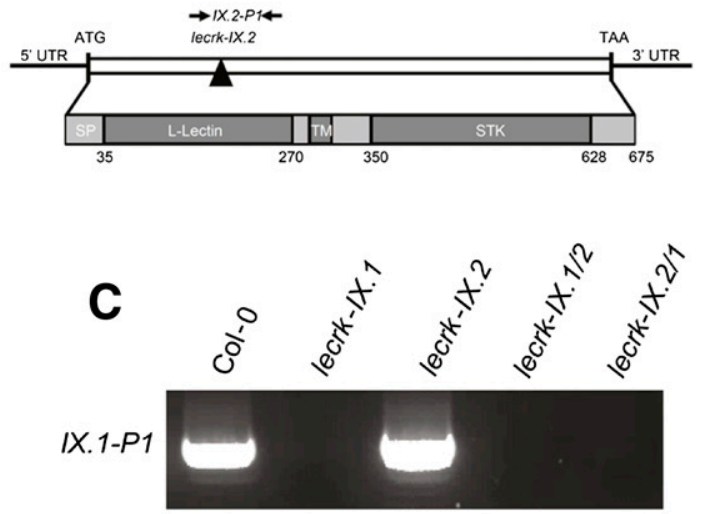

IX.2-P1

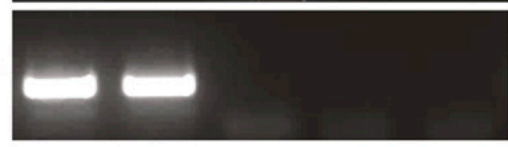

Actin2

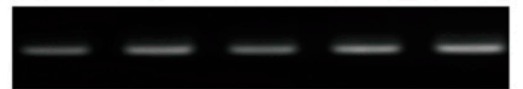

E

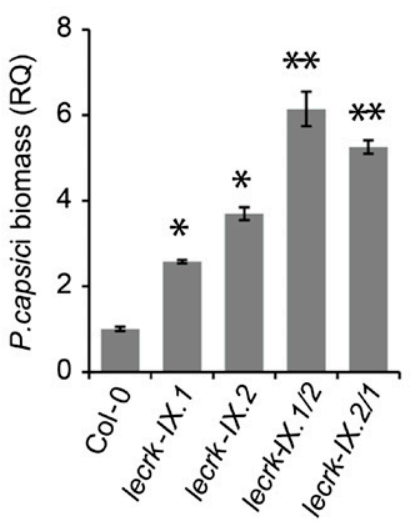

Fig. 1. Mutants lecrk-IX.1 and lecrk-IX.2 show defects in defense against Phytophthora pathogens. A, Expression of defense-related genes in lecrk-IX.1, lecrkIX.2, and Col-0 upon inoculation with P. capsici LT123. Arabidopsis leaves plug-inoculated with P. capsici isolate LT123 were harvested at 12 and $24 \mathrm{~h}$ postinoculation. Relative transcript levels were normalized to Arabidopsis Actin2. Values are expressed as mean fold changes ( \pm standard deviation [SD]) relative to the transcript level in mock-inoculated leaves. B, Schematic presentation of LecRK-IX.1 and LecRK-IX.2. Domains were predicted by SMART. Black arrowheads point to the T-DNA insertion sites and primers used for semi-quantitative reverse transcription-polymerase chain reaction (qRT-PCR) are indicated. TM = transmembrane domain, STK = kinase domain. C, Transcript levels of LecRK-IX.1 and LecRK-IX.2 in Col-0, lecrk-IX.1, lecrk-IX.2, and double mutants (i.e., lecrk-IX.1/2 and lecrkK-IX.2/1) determined by semi-qRT-PCR. Actin2 was used as control. D, Disease symptoms observed on Col-0, lecrk-IX.1, lecrk-IX.2, and double mutants 4 days postinoculation (dpi) with P. capsici LT123. White arrowheads point to the inoculated leaves. E, Relative quantification of P. capsici biomass in Col-0, lecrk-IX.1, lecrk-IX.2, and double mutants at 4 dpi by qPCR. For each sample, 12 inoculated leaves were pooled and were used for $P$. capsici biomass quantification. Bars represent mean values $( \pm \mathrm{SD})$ of three technical replicates relative to that of infected Col-0 leaves, which was arbitrarily set as 1 . One asterisk $(*)$ indicates significantly increased biomass $(P<0.05)$ when compared with Col- 0 , according to a $t$ test, while two asterisks $(* *)$ indicates significantly more biomass $(P<0.05)$ when compared with lecrk-IX.1 and lecrk-IX.2, according to a $t$ test. Experiments were repeated twice with similar results. 
line with these phenotypes, reduced $P$. capsici biomass was only detected in 35S-IX.1 and 35S-IX.2 lines when compared with that in Col-0 but not in the transgenic lines expressing lectin-deletion or kinase-dead mutants (Fig. 3D). Therefore, we conclude that both the lectin domain and the kinase activity of LecRK-IX.1 and LecRK-IX.2 are essential to mediate Phytophthora resistance.

Cell death induced by overexpression of LecRK-IX.I and $L e c R K-I X .2$ is not correlated with leaf senescence.

In silico gene expression analysis using publicly available microarray data indicated that LecRK-IX.2 but not LecRK-IX.1 is highly induced in senescent Arabidopsis leaves (Fig. 4A). This was verified by monitoring the transcript levels of LecRK$I X .1$ and LecRK-IX.2 by qRT-PCR in Col-0 leaves varying in senescence (Fig. 4B). LecRK-IX.1 showed no significant change in expression but LecRK-IX.2 expression levels increased in leaves with more severe symptoms of senescence (Fig. 4B). This expression pattern was comparable to that of $S A G 12$, a gene encoding a cysteine protease that has been widely used as a reliable senescence marker gene. SAG12 is only expressed in senescing tissues but not in stress- or hypersensitive response-related cell death (Noh and Amasino 1999; Pontier et al. 1999; Zhou

A

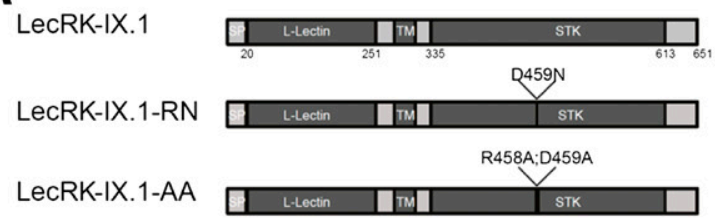

LecRK-IX.2

LecRK-IX.2-RN

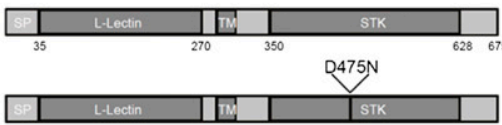

LecRK-IX.1-AA

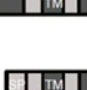

LecRK-IX.2-AA

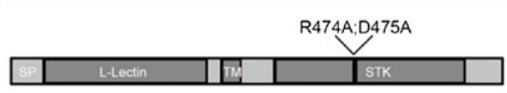

LecRK-IX.1-Dlectin

LecRK-IX.2-Alectin

B

Col-0

35S-IX.1-1

$35 S-I X .1-2$

$35 S-I X .1-R N-1$

35S-IX.2-1

35S-IX.2-2

$35 S-I X .2-R N-1$
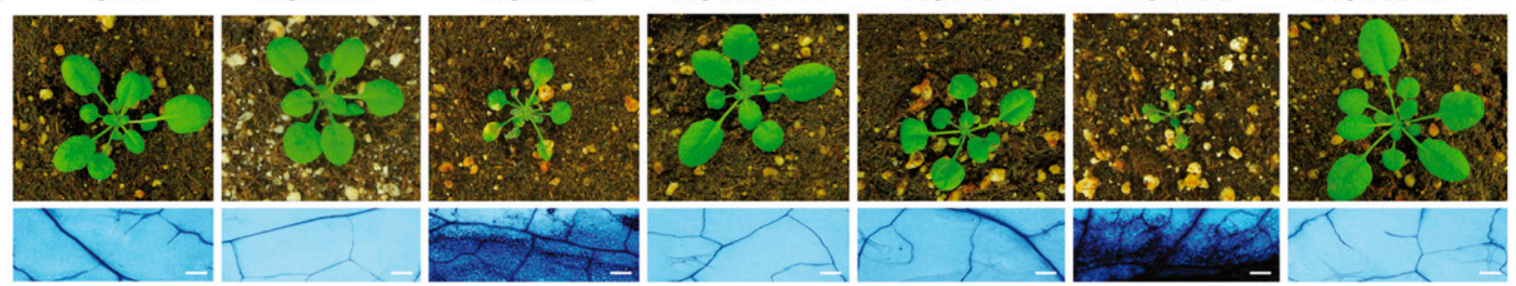

35S-GFP-1

35S-IX.1-Dlectin-1

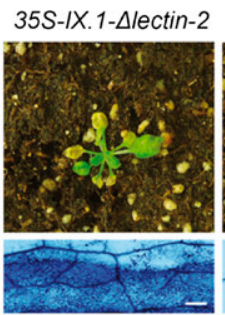

35S-IX.1-AA-1

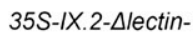

35S-IX.2--Llectin-2

$35 S-I X .2-A A-1$
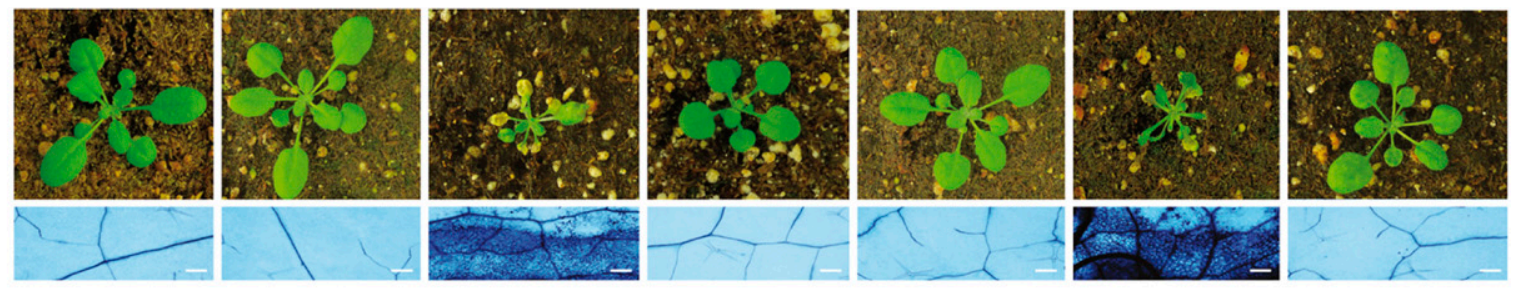

C
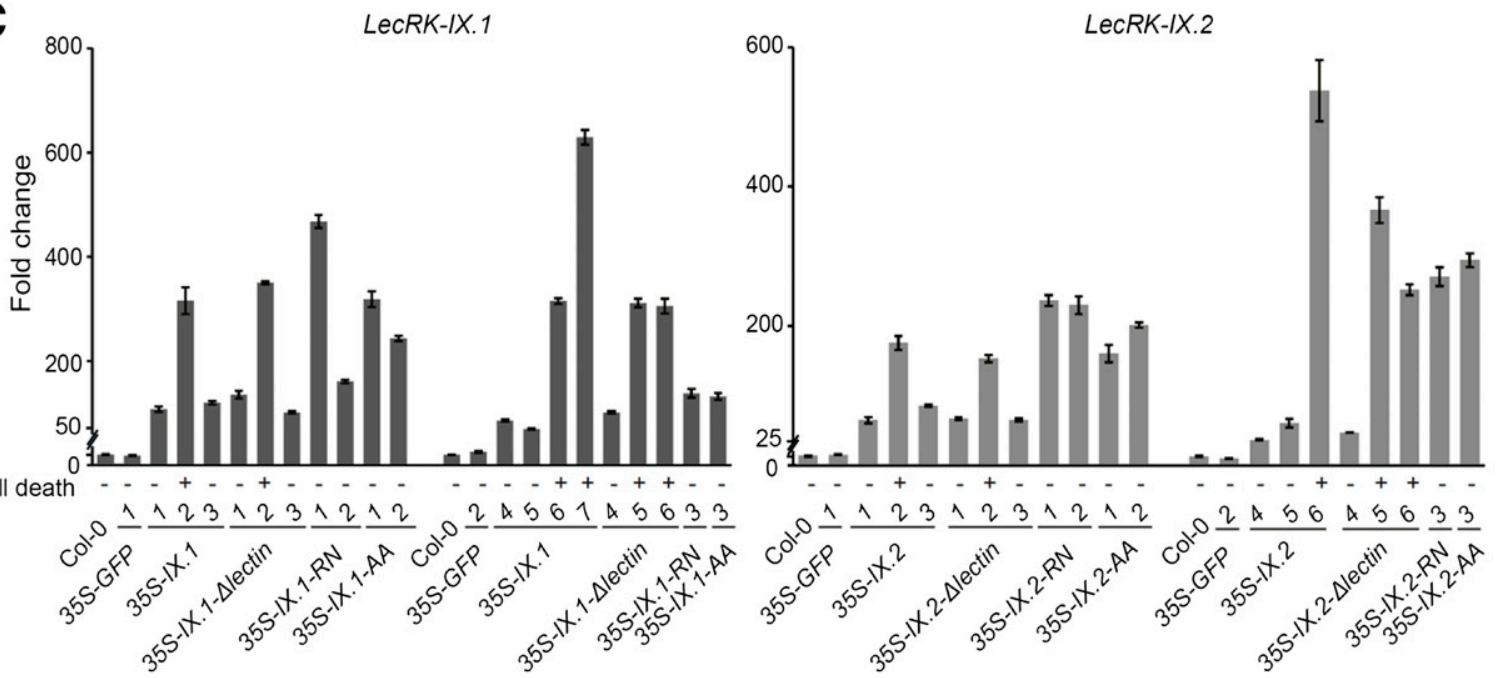

Fig. 2. Phenotypic changes of Arabidopsis transgenic lines expressing LecRK-IX.1, LecRK-IX.2, or derivatives lacking the lectin domain or mutated in the kinase domain. A, Schematic representation of LecRK-IX.1, LecRK-IX.2, and their derivatives, of which the coding sequences were cloned into binary vectors driven by the Cauliflower mosaic virus $35 \mathrm{~S}$ promoter for Arabidopsis Col-0 transformation. B, Growth of 24-day-old transgenic lines constitutively expressing LecRK-IX.1 and LecRK-IX.2 or their derivatives. Inset figures are microscopic images showing leaf sections upon trypan blue staining. Scale bars represent $200 \mu \mathrm{m}$. C, Correlation of plant cell-death phenotype and expression levels of LecRK-IX.1, LecRK-IX.2, or derivatives in different transgenic lines. Transcript levels were normalized to Arabidopsis Actin2 and values are expressed as mean fold changes ( \pm standard deviation) relative to the transcript level in Col-0 plants, which was arbitrarily set as $1 .+$ or - indicates transgenic lines with or without a cell-death phenotype. 
et al. 2009). We then compared the expression levels of $S A G 12$ in different LecRK-IX.2 transgenic lines with or without cell-death phenotype (Fig. 4C) but found no correlation between SAG12 expression and LecRK-IX.2 expression levels or plant phenotypic changes (Figs. 2C and 4C). This also holds for the LecRK-IX.1 transgenic lines (Figs. 2C and 4C). These results suggest that the cell-death phenotype induced by overexpression of LecRK-IX.1 or LecRK-IX.2 is not linked to plant senescence.

\section{Transient expression of LecRK-IX.1 or LecRK-IX.2 induces $\mathrm{H}_{2} \mathrm{O}_{2}$ production and cell death in $N$. benthamiana.}

To further confirm the role of LecRK-IX.1 and LecRK-IX.2 in Phytophthora resistance and cell-death induction, C-terminal GFP-tagged LecRK-IX.1 and LecRK-IX.2 were expressed in $N$. benthamiana using Agrobacterium-mediated transient gene expression and induced defense responses were analyzed.

To determine the accumulation of LecRK-IX.1-eGFP (enhanced GFP) and LecRK-IX.2-eGFP, total protein was isolated from the agroinfiltrated $N$. benthamiana leaves, and fractions immunopurified with GFP-trap_A beads were screened by Western blot with anti-GFP. Both fusion proteins could be detected, but the sizes were slightly larger than that of the in silico predicted monomers (Fig. 5A). Since LecRK contain putative $N$-glycosylation sites (Supplementary Fig. 4), the discrepancy in size could be partially due to glycosylation. This type of posttranslational modification has been shown to be important for some plant receptors in mediating immune responses (Häweker et al. 2010; Sun et al. 2012). For investigating whether the two LecRK are glycosylated, we used horseradish peroxidase (HRP) antibody, which detects $N$-glycans (Strasser et al. 2007; Liebrand et al. 2012). Purified LecRK-IX.1eGFP and LecRK-IX.2-eGFP detected with anti-HRP had similar sizes as those detected with anti-GFP (Fig. 5A), indicating that both LecRK-IX.1 and LecRK-IX.2 are $N$-glycosylated. In contrast, both lectin-deletion mutants showed hardly any signals with anti-HRP when compared with the full-length version, indicating that $N$-glycosylation mainly occurs on the lectin domain (Fig. 5A). This is in line with the number of predicted $\mathrm{N}$-glycosylation sites in the lectin domain (Supplementary Fig. 4). Also, the kinase-dead mutants could be detected with both anti-GFP and anti-HRP and showed similar sizes as the corresponding fulllength LecRK (Fig. 5A). It should be noted that, in all cases, there was less LecRK-IX.2 protein detected than LecRK-IX.1. Also, less LecRK-IX.1 and LecRK-IX.2 protein accumulated when compared with the kinase-dead mutants, indicating that the latter are more stable or show lower turnover rates.

A hallmark of defense following activation of receptors is the rapid production of ROS (Boller and Felix 2009). Hence, we monitored $\mathrm{H}_{2} \mathrm{O}_{2}$ production, using 3,3'-diaminobenzidine (DAB) staining in $N$. benthamiana upon transient expression of Arabidopsis LecRK-IX.1 and LecRK-IX.2. The left half of agroinfiltrated leaves expressing GFP did not show any distinguishable DAB staining, whereas the right half expressing LecRK-IX.1 or LecRK$I X .2$ clearly showed DAB staining, visualized as a brown precipitate (Fig. 5B). Coexpression with the silencing suppressor P19 resulted in more intense $\mathrm{DAB}$ staining, demonstrating significantly enhanced $\mathrm{H}_{2} \mathrm{O}_{2}$ production (Fig. 5B). Irrespective of P19, DAB staining was always stronger in leaves expressing LecRK-IX.2 than those expressing LecRK-IX.1, indicating that the presence of LecRK-IX. 2 causes greater $\mathrm{H}_{2} \mathrm{O}_{2}$ production (Fig. 5B). In contrast, DAB staining was not observed in leaves expressing another LecRK, i.e., LecRK-S.4. Also the spontaneous cell-death phenotype that was observed in leaves expressing LecRK-IX.2 was much stronger than in leaves expressing LecRK-IX.1 (Fig. 5C). The extent of cell death was quantified by measuring ion leakage, showing that the conductivity was higher in $N$. benthamiana leaves expressing LecRK-IX.2 than in those expressing LecRK-IX.1 (Fig. 5D). Upon coexpression with P19, LecRK-IX.1 produced a slightly delayed but, eventually, a similar extent of cell death as LecRK-IX.2 (Fig. 5C and D). None of the leaves expressing GFP with or without P19 showed any visible cell death (Fig. 5C and D).

Unlike expression of kinase-dead mutants, expression of the lectin-deletion mutant of LecRK-IX.1 or LecRK-IX.2 in $N$. benthamiana induced a similar extent of $\mathrm{H}_{2} \mathrm{O}_{2}$ production and cell death as expression of the full-length proteins (Fig. 5E and F). Collectively, these results show that the kinase activity but not the lectin domain plays a role in LecRK-IX.1- and LecRK-IX.2mediated $\mathrm{H}_{2} \mathrm{O}_{2}$ production and cell-death induction.

\section{Silencing of NbSIPK/NTF4 abolishes \\ LecRK-IX.1-induced cell death in $N$. benthamiana.}

To identify downstream signaling components required for LecRK-IX.1- and LecRK-IX.2-induced cell death in N. benthamiana, we analyzed the role of several genes known to be involved in cell-death induction in $N$. benthamiana using Tobacco rattle virus (TRV)-mediated virus-induced gene silencing (VIGS). These included the salicylic acid signaling genes NbNPRI and NbEDS1, the MAPK genes NbMEK2 and NbSIPK/NTF4, the HR-associated nucleotide binding-leucine-rich repeat gene $N b N R C 1$, and the NADPH oxidase gene pair NbRbohA/B (Gabriëls et al. 2006, 2007; Rustérucci et al. 2001; Takahashi et al. 2007; Yoshioka et al. 2003). TRV:GUS ( $\beta$-glucuronidase)-treated plants were used as control. Three to four weeks after TRV inoculation, LecRK-IX.1eGFP, LecRK-IX.2-eGFP, and GFP were expressed in leaves, using agroinfiltration. In all cases, expression of LecRK-IX.1-eGFP or LecRK-IX.2-eGFP resulted in cell death on TRV:GUS-treated plants (Fig. 6A). Similarly, cell death was observed in leaves silenced for $N b E D S 1, N b N R C 1$, and $N b R b o h A / B$, whereas it was attenuated in leaves silenced for $N b M E K 2$ or $N b N P R 1$ (Supplementary Fig. 5). These results indicate that LecRKmediated cell death is not dependent on NbEDS1, NbNRC1, or NbRbohA/B but is partially dependent on NbMEK2 and NbNPR1. In contrast, cell death induced by LecRK-IX.1-eGFP was completely abolished in leaves silenced for $N b S I P K$ and its closest homolog NbNTF4 (Fig. 6A). The efficiency of silencing was shown to be close to $100 \%$ (Fig. 6B). Loss of LecRK-IX.1induced cell death in NbSIPK/NTF4-silenced leaves was confirmed by staining with trypan blue (Fig. 6C). In addition, cell death induced by LecRK-IX.2-eGFP was also remarkably compromised in the NbSIPK/NTF4-silenced leaves (Fig. 6A and C) but, under the same conditions, cell death elicited by the Phytophthora elicitor NPP1 was not altered. Compared with those treated by TRV:GUS, leaves silenced for $N b S I P K / N T F 4$ showed a slight delay in celldeath development but, eventually, the extent of cell death

Fig. 3. Infection of Phytophthora capsici on Col-0 and transgenic lines expressing LecRK-IX.1, LecRK-IX.2, or derivatives lacking the lectin domain or mutated in the kinase domain. A, Disease symptoms on Col-0 and transgenic lines 35S-GFP, 35S-IX.1-1, and 35S-IX.2-1 3 days after plug-inoculation with $P$. capsici LT263. White arrowheads point to the inoculated leaves. B, Microscopic investigation of $P$. capsici infection. Leaves inoculated with $P$. capsici LT263 zoospores $\left(10^{5}\right.$ zoospores per milliliter) were harvested at $12 \mathrm{~h}$ postinoculation and were stained with trypan blue. White arrowheads point to the penetration sites, while black arrowheads point to papillae. hy = invasive hyphae. Scale bars represent $25 \mu \mathrm{m}$. $\mathbf{C}$ and $\mathbf{D}$, Disease symptoms on Col-0 and different transgenic lines at 3 days postinoculation (C) and P. capsici biomass (D). In C, white arrowheads point to the inoculated leaves. In D, bars represent mean values ( \pm standard deviation) of three technical replicates relative to that of infected Col-0 leaves, which was arbitrarily set as 1 . An asterisk (*) indicates significant difference in biomass $(P<0.05)$ according to a $t$ test. Experiments were repeated twice with similar results. 
induced by NPP1 was comparable (Fig. 6A). In line with this, NbSIPK/NTF4-silenced leaves expressing LecRK-IX.1-eGFP or LecRK-IX.2-eGFP showed a significant reduction in ion leakage compared with TRV:GUS-treated leaves; but, for leaves expressing NPP1, this was not the case (Fig. 6D). To determine whether the loss of cell death observed in NbSIPK/NTF4-silenced plants is due to reduced accumulation of LecRK-IX.1, GFP, and LecRK-IX.1-eGFP protein levels were determined, but no
A

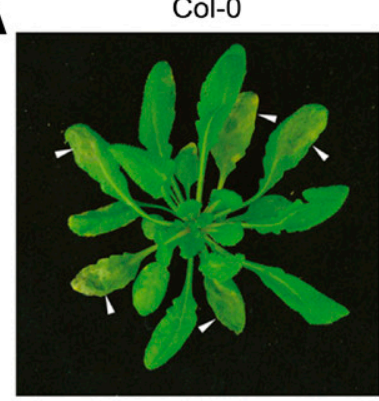

B

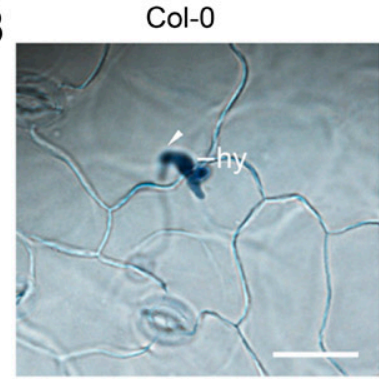

35S-GFP

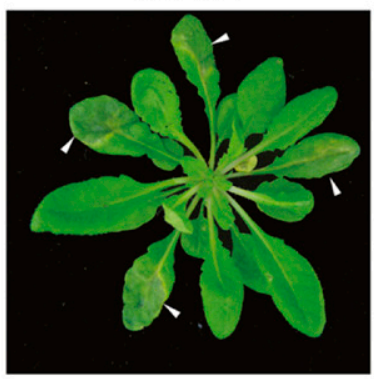

35S-GFP

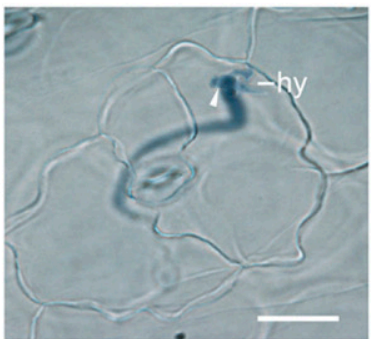

$35 S-I X .1-1$

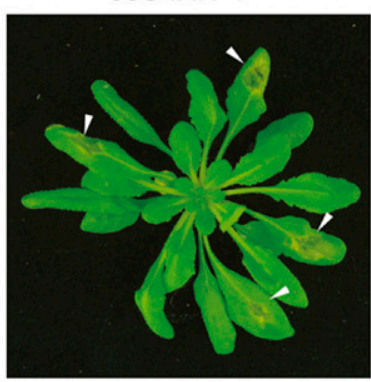

$35 S-I X .1-1$

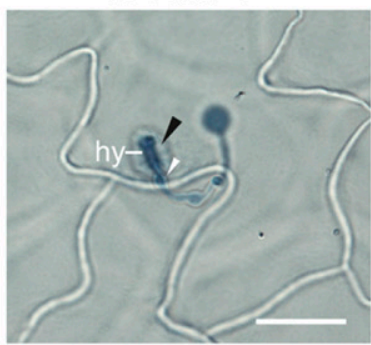

$35 S-I X .2-1$

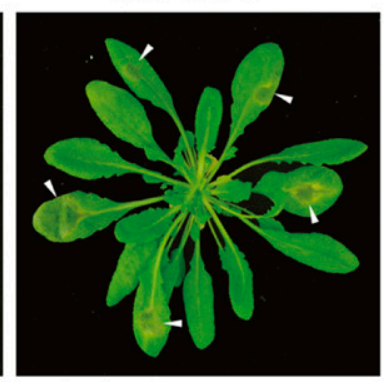

$35 S-I X .2-1$

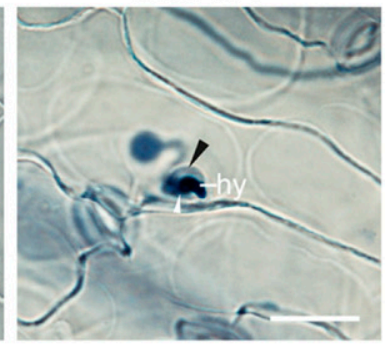

$35 S-I X .1-A A-1$

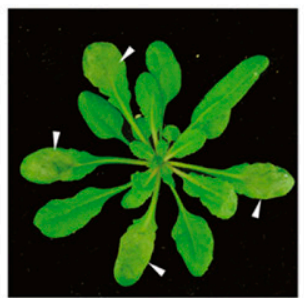

$35 S-I X .2-R N-1$

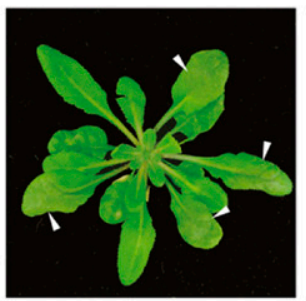

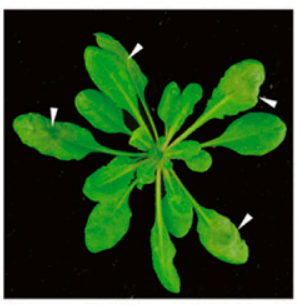

$35 S-I X .2-A A-1$

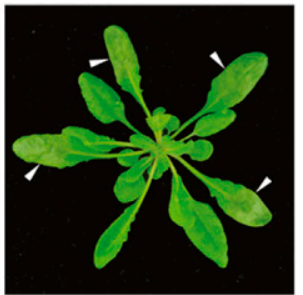

D

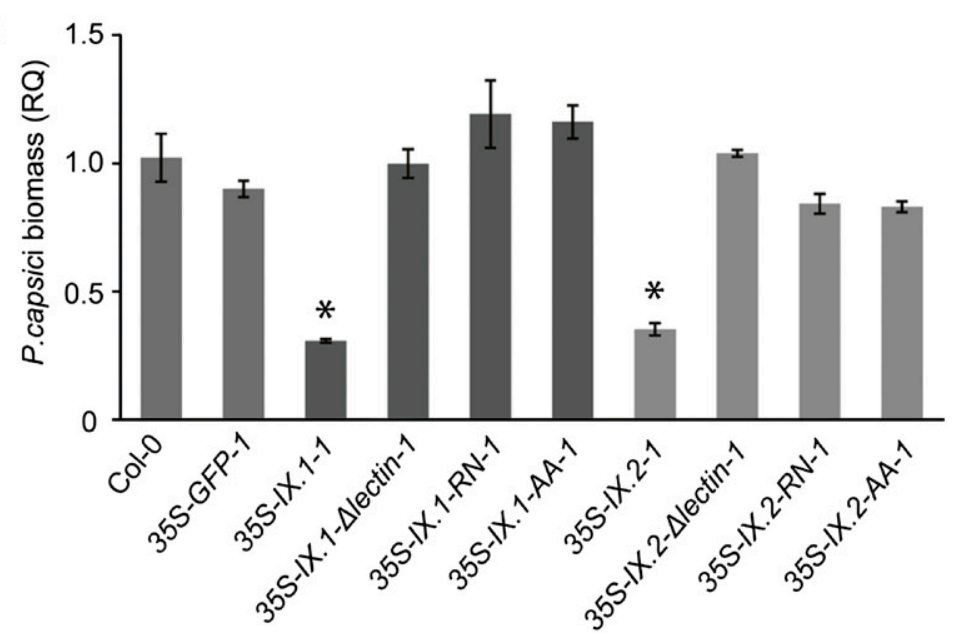


differences were found when compared with those detected in the TRV:GUS-treated plants (Fig. 6E). In conclusion, NbSIPK or NbNTF4, or both, are indispensable downstream signaling components for LecRK-IX.1- and LecRK-IX.2-mediated cell death.

\section{Silencing of NbSIPK/NTF4 compromises LecRK-IX.1- mediated Phytophthora resistance in $N$. benthamiana.}

To determine whether LecRK-IX.1 and LecRK-IX.2 are capable to enhance Phytophthora resistance in $N$. benthamiana, we inoculated P. capsici on $N$. benthamiana leaves with one half of the leaf expressing GFP and the other half LecRK-IX.1-eGFP or LecRK-IX.2-eGFP. Disease symptoms were evaluated at $3 \mathrm{dpi}$. In the presence of LecRK-IX.1-eGFP, lesion sizes were significantly reduced (Fig. 7A). Leaves expressing LecRK-IX.2 showed severe cell death and were not included in the infection assays (Fig. 5C).

Host cell death often associates with disease resistance, especially against (hemi)biotrophic pathogens (Mur et al. 2008). Absence of LecRK-IX.1-induced cell death in NbSIPK/NTF4silenced plants raised the possibility that also the resistance function of LecRK-IX.1 might be affected. Hence, we transiently expressed LecRK-IX.1-eGFP and GFP in TRV:GUS- or TRV: $N b S I P K / N T F 4$-treated plants and inoculated these plants with $P$. capsici. Lesion sizes on TRV:GUS-treated leaves expressing LecRK-IX.1-eGFP were significantly reduced compared with those expressing GFP (Fig. 7B). Also TRV:NbSIPK/NTF4-treated leaves expressing LecRK-IX.1-eGFP showed reduced lesion sizes compared with those expressing GFP, but the reduction in lesion size was not as strong as on TRV:GUS-treated leaves (Fig. 7B). This indicates that silencing of NbSIPK/NTF4 did not completely abolish the function of LecRK-IX.1 in resistance to $P$. capsici. Since cell death was completely abolished in NbSIPK/NTF4-silenced leaves, it can be concluded that LecRK-IX.1-mediated Phytophthora resistance is not entirely a consequence of induced cell death. It is likely that additional components or responses other than cell death play a role in inhibiting Phytophthora colonization.

\section{LecRK-IX.1 and LecRK-IX.2 associate with $N$. benthamiana NbPDR1 and Arabidopsis ABCG40 in planta.}

To identify potential LecRK-interacting proteins, our idea was to coimmunoprecipitate proteins that form a complex with the eGFP-tagged LecRK-IX.1 and eGFP-tagged LecRKIX.2 in the stable transgenic Arabidopsis lines and, subsequently, to analyze these coimmunoprecipitated proteins by LC-MS. However, we were unable to purify sufficient amounts of protein for LC-MS analysis, either because transgene expression was too low or because lines with a relative higher transgene expression showed severe cell death (Fig. 2). Since Arabidopsis LecRK-IX.1 and LecRK-IX.2 retained their function when transiently expressed in $N$. benthamiana, we anticipated that, also, the interaction partners might be conserved in the two plant species. Hence, we transiently expressed LecRK-IX.1-eGFP, LecRK-IX.2eGFP, and the control GFP in N. benthamiana and analyzed the (co)immunoprecipitated proteins with LC-MS after trypsin digestion. The resulting masses were used as queries for screening the protein database containing sequences from $N$. benthamiana and the input LecRK and GFP. A large number of peptides matching LecRK-IX.1 and LecRK-IX.2 were detected, demonstrating successful purification of the input LecRK (Fig. 8A). Further analysis revealed a potential candidate that was detected only in the LecRK samples but not in the control GFP sample. Multiple peptides in both the LecRK-IX.1 and LecRK-IX.2 samples match uniquely to NbPDR1 (NbS00038999g0004.1), a pleiotropic drug resistance-type ABC (ATP-binding cassette) transporter (Fig. 8A and B; Supplementary Tables S2 and S3). This suggests that both LecRK-IX.1 and LecRK-IX. 2 interact with NbPDR1 in planta.

We then determined the interaction of both LecRK with Arabidopsis ABCG40 (alias PDR12), the closest homolog of NbPDR1 in Arabidopsis. LecRK-IX.1-eGFP, LecRK-IX.2-eGFP, or GFP were coexpressed with ABCG40-Myc in N. benthamiana and were immunoprecipitated using GFP-trap_A beads. As shown by Western blots probed with c-Myc antibody, ABCG40-Myc coimmunoprecipitated with both LecRK-IX.1-eGFP and LecRKIX.2-eGFP but not with GFP (Fig. 8C; Supplementary Fig. 6), demonstrating that Arabidopsis ABCG40 interacts with the two clade IX LecRK in planta.

\section{Arabidopsis ABCG40 is a potential \\ Phytophthora resistance component.}

To determine the biological relevance of the interaction between ABCG40 and the two LecRK, we monitored the expression of $A B C G 40$ in Col-0 and LecRK mutants during infection with $P$. capsici LT123. In Col-0, expression of $A B C G 40$ was increased significantly from 12 to $24 \mathrm{~h}$ postinoculation. In comparison, the expression levels were much lower in both lecrk-IX.1 and lecrk-IX.2 (Fig. 9A), indicating that ABCG40 may function downstream of the two LecRK. To determine the role of ABCG40 in Phytophthora resistance, two homozygous Arabidopsis mutants, i.e., abcg40-1 and abcg40-2 with T-DNA insertions in the coding regions (Fig. 9B), were analyzed in Phytophthora infection assays. Absence of $A B C G 40$ expression in the mutants was confirmed by semi-qRT-PCR (Fig. 9C). Upon inoculation with $P$. capsici LT123, both lines developed clear disease symptoms at $4 \mathrm{dpi}$, while Col-0 plants remained fully resistant (Fig. 9D). The gain of susceptibility of the two ABCG40 mutants was also consistent with increased $P$. capsici biomass (Fig. 9E). In addition, both mutants showed compromised resistance to $P$. brassicae $\mathrm{HH}$ (Supplementary Fig. 7). This points to a function for $A B C G 40$ in Phytophthora resistance.

\section{DISCUSSION}

As one of the largest RLK subfamilies in Arabidopsis, LecRK are considered to play diverse roles in plant adaptation. In recent years, detailed studies on three members of this subfamily, i.e., Arabidopsis LecRK-I.9, LecRK-V.5, and LecRK-IV.2, revealed their importance in plant immunity (Bouwmeester et al. 2011; Desclos-Theveniau et al. 2012; Singh et al. 2012). In this study, we focus on two Arabidopsis LecRK belonging to clade IX, namely LecRK-IX.1 and LecRK-IX.2, which were

Fig. 4. Cell death induced by overexpression of LecRK-IX.1 or LecRK-IX.2 is not correlated with leaf senescence. A, Expression profiles of $L e c R K-I X .1$ and LecRK-IX.2 in different Arabidopsis leaves deduced from a publicly available microarray dataset (ArrayExpress accession number E-AFMX-9). Signal intensity $\log _{2}$ ratios range from -2 (dark shading) to 6 (light shading), as indicated in the scale bar. B, Expression levels of LecRK-IX.1, LecRK-IX.2, and SAG12 in Col-0 leaves varying in senescence. Relative transcript levels were normalized to Arabidopsis Actin 2 and values are expressed as mean fold changes ( \pm standard deviation) relative to that in Col-0 leaves at senescence stage 1 (S1), which was arbitrarily set as 1 . C, Expression levels of SAG12 in Col-0 and different transgenic lines. Total RNA was isolated from the whole rosette of 24-day-old Arabidopsis (inset figures) and was used for quantitative reverse transcription-polymerase chain reaction. Relative transcript levels were normalized to Arabidopsis Actin2, and values are expressed as mean fold changes ( \pm standard deviation) relative to the transcript levels in Col-0 plants, which was arbitrarily set as 1. 
A

Cotyledon

Cauline leaf

Rosette leaf 2

Rosette leaf 4

Rosette leaf 6

Rosette leaf 8

Rosette leaf 10

Rosette leaf 12

Senescing leaf

Vegetative rosette

$\log _{2}$

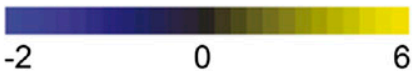

B

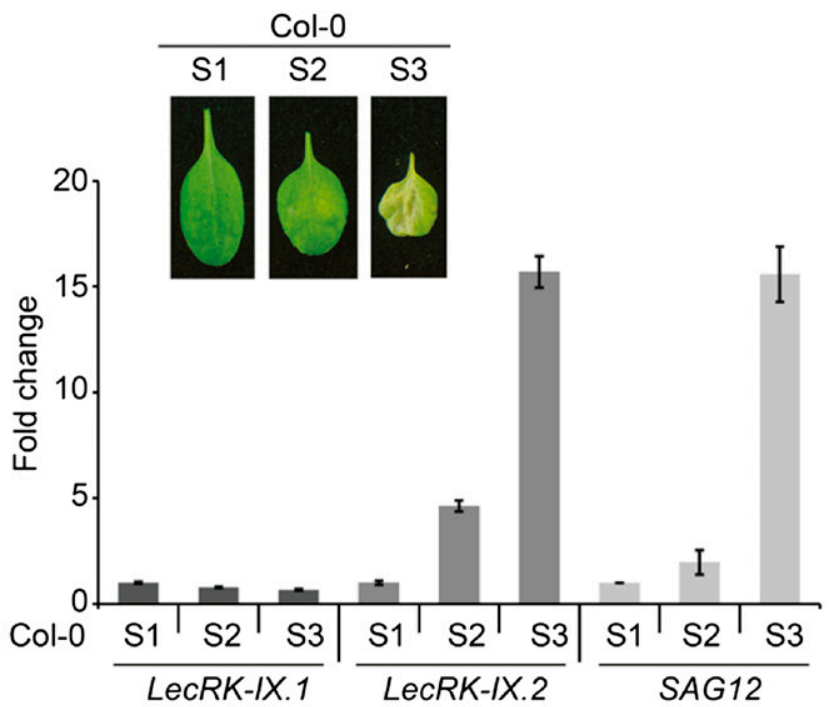

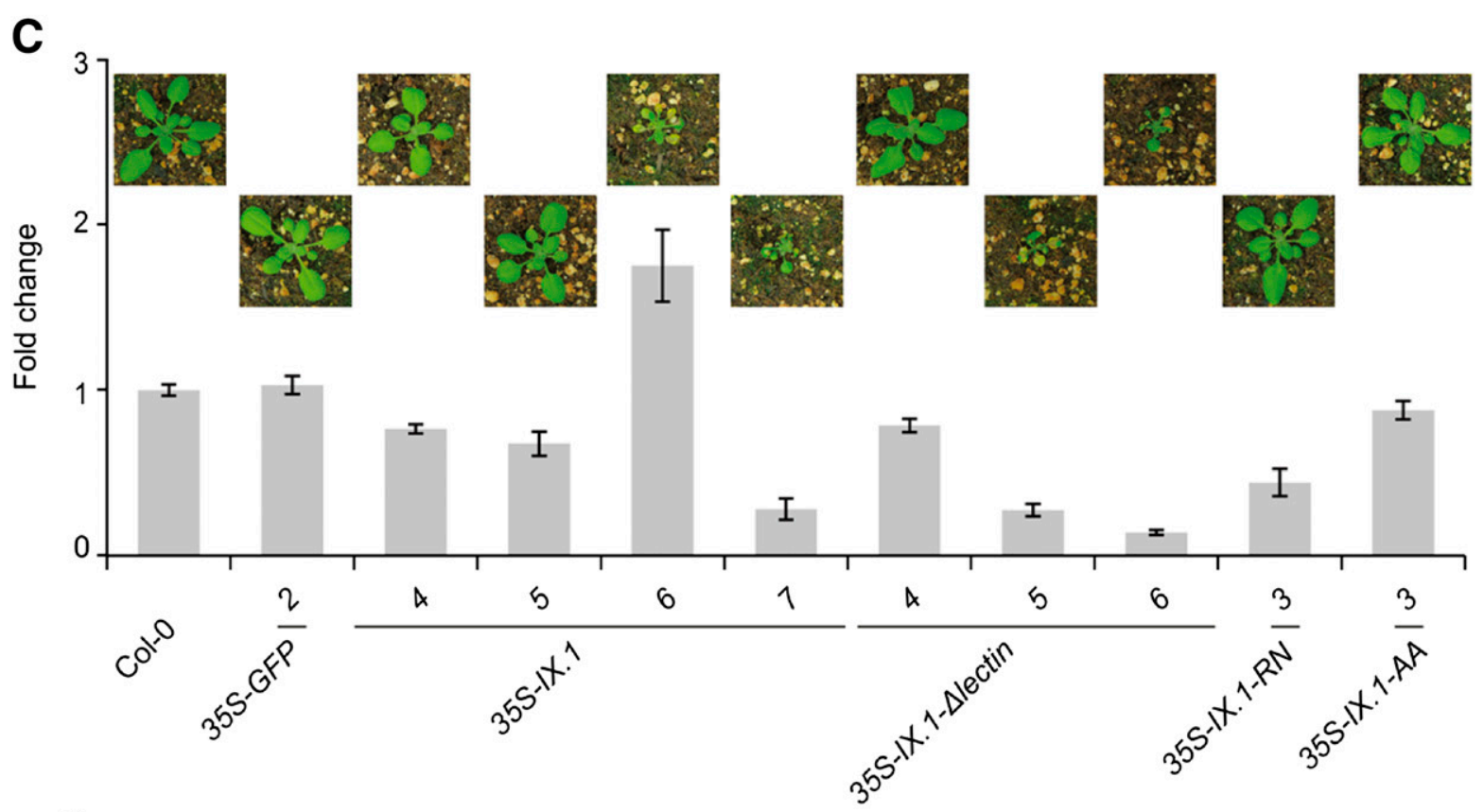

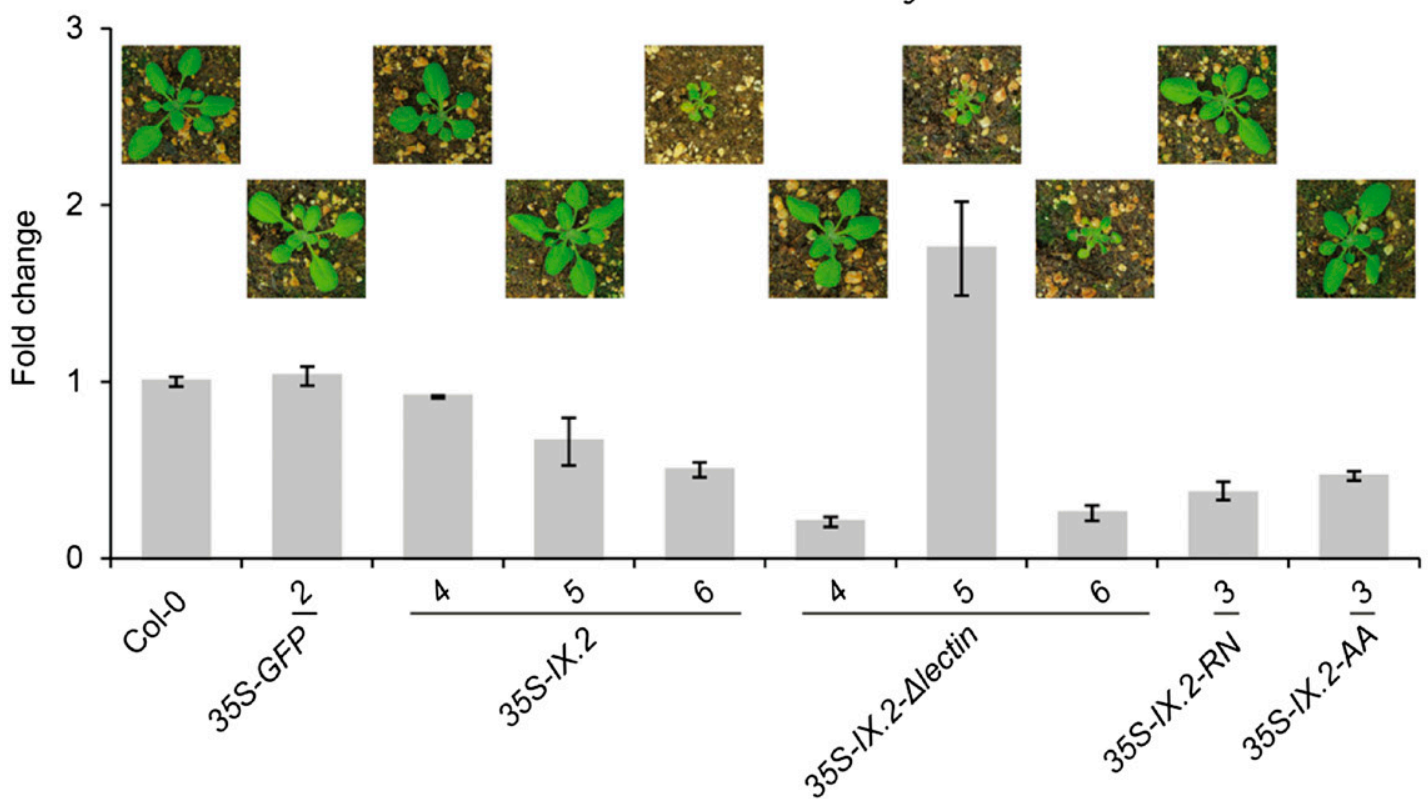

Vol. 28, No. 9, 2015 / 1039 
previously identified as potential Phytophthora resistance components, based on phenotypic analyses of T-DNA insertion lines (Wang et al. 2014). We confirmed the role of LecRK-IX.1 and LecRK-IX.2 in Phytophthora resistance and found that they act as functional analogs but are not functionally redundant. Knockout of either LecRK-IX.1 or LecRK-IX.2 in Arabidopsis leads to a gain of susceptibility to Phytophthora pathogens and reduced expression of defense-related genes upon infection. Overexpression of each of the two in Arabidopsis increases Phytophthora resistance but also induces spontaneous plant cell death, in particular in transgenic lines with a relatively high transgene expression level. In addition, LecRK-IX.1 retained its function as a Phytophthora resistance component when transiently expressed in the solanaceous plant $N$. benthamiana. Both LecRK also induced cell death when expressed in $N$. benthamiana, suggesting conservation of downstream components for LecRKmediated signaling in different plant species. They were both found to associate with $\mathrm{ABC}$ transporters, suggesting that they participate in the same signaling network. In Arabidopsis, the ABC transporter ABCG40 turned out to be a potential Phytophthora resistance component; the two independent $A B C G 40$ T-DNA mutants tested in this study both showed compromised resistance to Phytophthora pathogens.

Programmed cell death often occurs in response to pathogen invasion (Coll et al. 2011; Dickman and de Figueiredo 2013; Dickman and Fluhr 2013). The effect of cell death on plant resistance depends largely on the lifestyle of the invading pathogen. In general, activation of cell death at early infection stages often limits proliferation of biotrophic and hemibiotrophic pathogens but promotes infection of necrotrophic pathogens. Several reports, however, showed that plant cell death is not always essential for resistance (Genger et al. 2008; Takahashi et al. 2012; $\mathrm{Yu}$ et al. 1998). The cell-death phenotype induced by overexpression of LecRK-IX.1 and LecRK-IX.2 raised the question whether cell death is involved in LecRK-mediated Phytophthora resistance. Here, we provide three lines of evidence to show that LecRK-mediated Phytophthora resistance is not due to induction of cell death. First of all, for both LecRK, increased Phytophthora resistance was detected in transgenic Arabidopsis lines that did not show the cell-death phenotype. The intensity of cell death was found to be correlated with transgene expression levels. Cell death was only observed in transgenic lines with relative high LecRK-IX.1 or LecRK-IX.2 expression levels, whereas LecRKmediated Phytophthora resistance was also found in the lines with relative low transgene expression. Microscopic analysis showed that Phytophthora infection on Arabidopsis LecRK overexpression lines did not cause increased cell death. Secondly, the lectin domain was found to be required for LecRK-mediated Phytophthora resistance but dispensable for cell-death execution. The importance of the lectin domain for the biological function of LecRK was also demonstrated by the finding that the lectin domain of LecRK-I.9 interacts with the Phytophthora infestans effector IPI-O and binds to eATP (Bouwmeester et al. 2011; Choi et al. 2014; Gouget et al. 2006). Apparently, the extracellular lectin domain is required for monitoring pathogen attack by recognizing either effectors or PAMPs of Phytophthora or DAMPs released upon infection. This recognition could, in turn, lead to activation of plant defense mediated by the kinase domain. The spontaneous cell-death phenotype may be a consequence of constitutive activation of pathogen-independent responses, such as production of ROS that has been shown to play a prominent role in the execution of plant cell death (Van Breusegem and Dat 2006). Along with induced cell death, elevated $\mathrm{H}_{2} \mathrm{O}_{2}$ production was detected in $N$. benthamiana expressing LecRK-IX.1 or LecRK-IX.2, either full-length or truncated versions lacking the lectin domain. This indicates that the $\mathrm{H}_{2} \mathrm{O}_{2}$ production induced by expression of LecRK-IX.1 or LecRK-IX.2 is tightly correlated with cell-death induction, although the possibility that the LecRK are involved in regulating plant cell death cannot be excluded. The latter was found for SOBIR1, an Arabidopsis RLK that also activates plant cell death upon overexpression (Gao et al. 2009). The third line of evidence is that LecRK-mediated cell death and Phytophthora resistance in $N$. benthamiana require different downstream components. One of the important events leading to plant cell death is the sequential activation of MAPK cascades (Meng and Zhang 2013). By VIGS in N. benthamiana, we found NbSIPK and NbNTF4 to be essential for LecRK-IX.1- and LecRK-IX.2-mediated cell death. The MAPK NbSIPK and NbNTF4 are close homologs and both have been shown to be involved in defense responses downstream of receptors and capable of inducing cell death when expressed in $N$. benthamiana (Asai et al. 2008; Huang et al. 2014; Ren et al. 2006; Segonzac et al. 2011; Zhang and Liu 2001). Silencing of NbSIPK and NbNTF4 completely abolished LecRK-IX.1-mediated cell death, whereas Phytophthora resistance was decreased but not completely lost. This indicates that NbSIPK and NbNTF4 participate in but do not determine LecRK-IX.1mediated Phytophthora resistance in $N$. benthamiana.

For RLK, the kinase domain was found to be crucial in initiating signal transduction via phosphorylation of downstream substrates, as point mutations often abolish RLK-mediated functions (Gómez-Gómez et al. 2001; Liebrand et al. 2013; Morillo and Tax 2006; Schwessinger et al. 2011). Although it is very likely that the kinase domains of the various LecRK have a similar role in signal transduction, there is only one documented example so far, i.e., rice SIT1, for which the kinase activity is essential for its function in mediating salt sensitivity (Li et al. 2014). Of the 45 Arabidopsis LecRK, only LecRKVI.2 has been shown to autophosphorylate in vitro (Singh et al. 2013), but whether this kinase activity is essential for its role in priming plant defense is thus-far unknown. In this study, we analyzed the relevance of the kinase activity of LecRK-IX.1 and LecRK-IX.2 for mediating resistance and cell-death induction. LecRK are RD kinases with an aspartate (D) in the catalytic loop preceded by a conserved arginine (R) (Kornev et al. 2006; Nolen et al. 2004). It has been demonstrated that mutation of the conserved RD motif into RN or AA blocks kinase activity (Schwessinger et al. 2011; van Damme et al. 2012). We found that, upon mutation of the RD motif, both LecRK-mediated Phytophthora resistance as well as cell death was completely abolished. These results demonstrated that the two LecRK harbor an active kinase and that kinase activity is indispensable for their function.

Plant receptors do not work alone but rather function as part of multiprotein complexes (Liebrand et al. 2014; Macho and Zipfel 2014). Recently, one of the Arabidopsis LecRK, namely LecRKVI.2, was found to associate with the flagellin receptor FLS2 and to prime flg22-mediated defense in Arabidopsis and N. benthamiana (Huang et al. 2014). In this study, the identification of potential LecRK-IX.1- and LecRK-IX.2-interacting proteins in Arabidopsis was hampered by the severe cell-death phenotype but, fortunately, the conserved function of the two LecRK in $N$. benthamiana allowed us to exploit $N$. benthamiana as a convenient alternative. This resulted in the identification of NbPDR1 and its closest Arabidopsis homolog ABCG40 as potential LecRK-interacting proteins. They both belong to the pleiotropic drug resistance (PDR) subfamily of plant $\mathrm{ABC}$ transporters, of which several members have been implicated in pathogen growth inhibition and transport of sclareol-like diterpenes (Rea 2007; van den Brûle and Smart 2002). In tobacco, for example, inhibition of bacterial wilt disease by sclareol was attenuated upon silencing of NtPDRl (Seo et al. 2012) and, in Nicotiana plumbaginifolia, NpPDR1 was shown to contribute not only to transport of sclareol but also to resistance against several fungi and the oomycete Phytophthora nicotianae (Bultreys et al. 2009; Stukkens et al. 2005). In Arabidopsis, ABCG40 functions as an abscisic acid (ABA) uptake transporter 


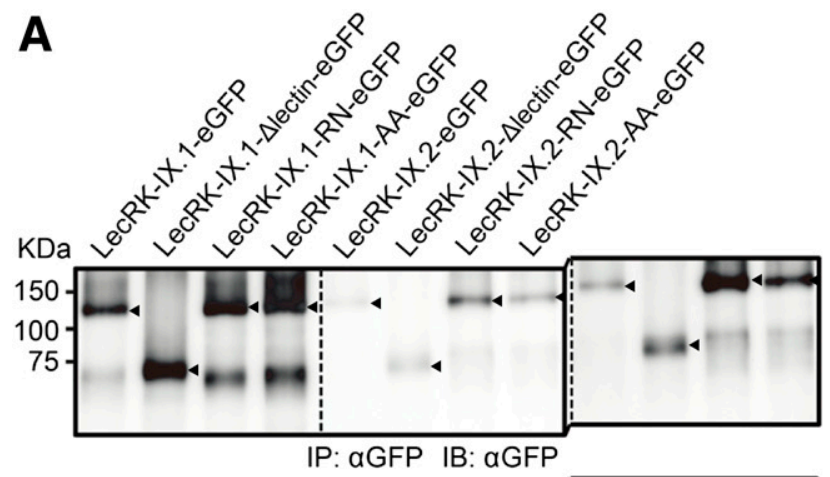

\section{C}
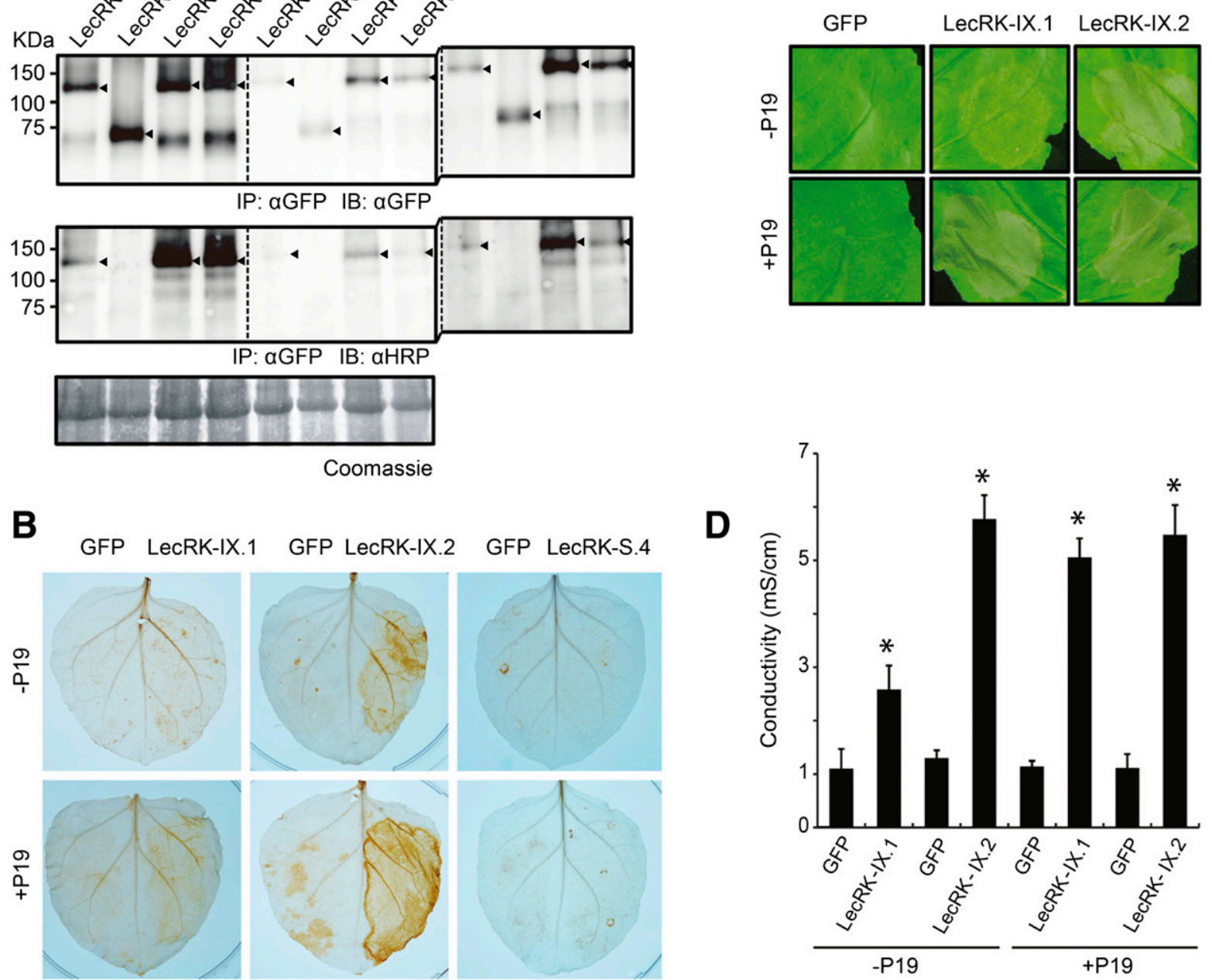

B

GFP LecRK-IX.1 GFP LecRK-IX.2 GFP LecRK-S.4

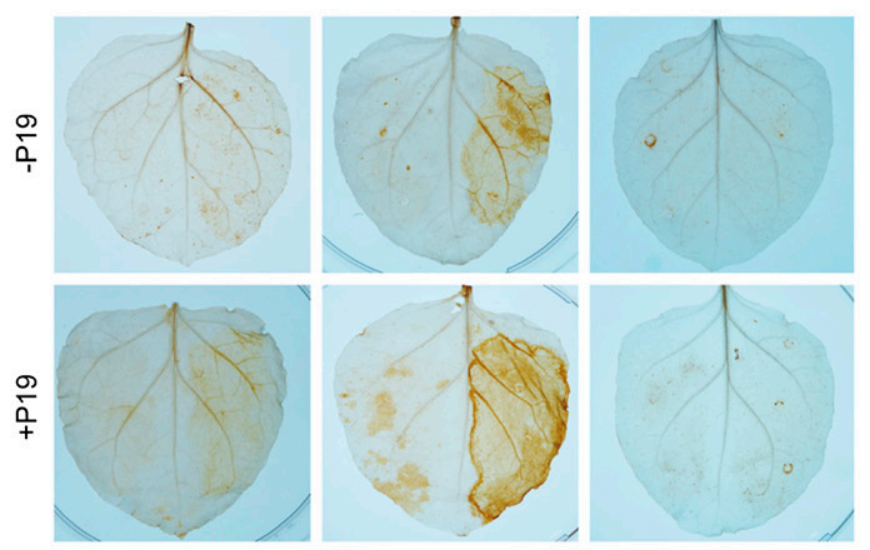

$\mathbf{F}$
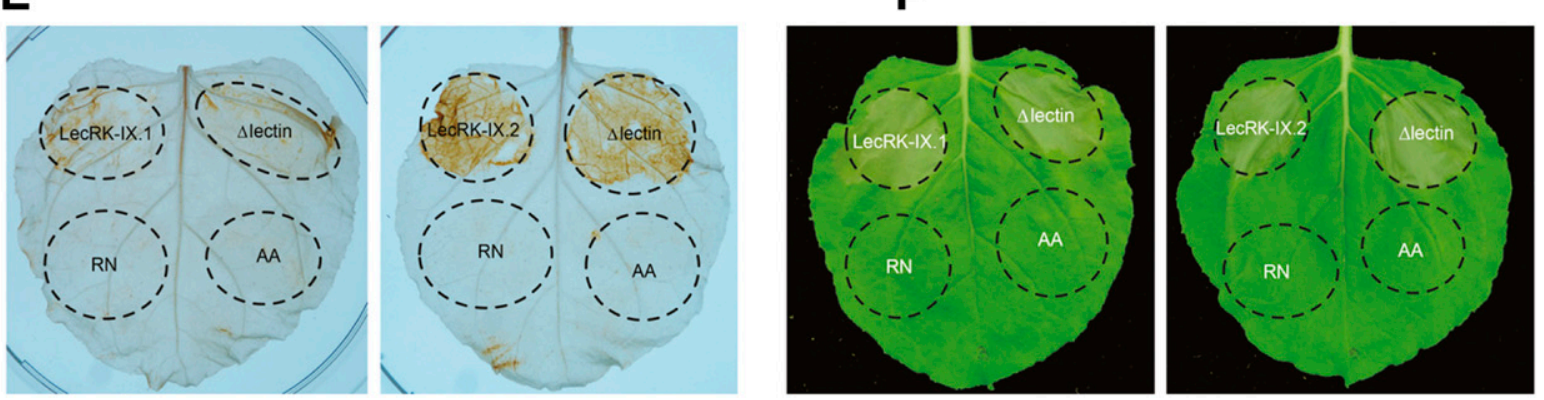

Fig. 5. $\mathrm{H}_{2} \mathrm{O}_{2}$ accumulation and cell death induced by transient expression of LecRK-IX.1, LecRK-IX.2, and derivatives in Nicotiana benthamiana. A, LecRKIX.1-eGFP, LecRK-IX.2-eGFP, and derived mutants are expressed and glycosylated in $N$. benthamiana. Green fluorescent protein (GFP)-tagged LecRK, lectindeletion, and kinase-dead mutants were coexpressed with P19 in N. benthamiana by Agrobacterium-mediated transformation. The right half of the blot that contains LecRK-IX.2-eGFP and derivatives is also shown with a longer exposure. Total protein was isolated and subjected to immunopurification using GFPtrap_A beads. The immunopurified proteins (IP) were detected by Western blot (IB) with anti-GFP or anti-HRP (horseradish peroxidase). Black arrowheads indicate the position of eGFP-tagged LecRK-IX.1, LecRK-IX.2, and derivatives. Coomassie staining shows the 50-kDa Rubisco band indicating equal loading in each lane. B, $\mathrm{H}_{2} \mathrm{O}_{2}$ accumulation in $N$. benthamiana leaves expressing GFP, LecRK-IX.1-eGFP, LecRK-IX.2-eGFP, and LecRK-S.4-eGFP with (+P19) or without P19 (-P19). Leaves were collected 2 days after agroinfiltration (dpa), were stained with 3,3'-diaminobenzidine (DAB) solution, and were destained with ethanol. C, Cell death on $N$. benthamiana leaves expressing GFP, LecRK-IX.1-eGFP, and LecRK-IX.2-eGFP with (+P19) or without P19 (-P19) at 3 dpa. D, Quantification of cell death induced by expression of LecRK-IX.1-eGFP and LecRK-IX.2-eGFP in N. benthamiana by ion leakage measurements. Bars represent mean values ( \pm standard error) of six replicates from each experiment. Asterisks $\left(^{*}\right)$ indicates significant difference $(P<0.05)$, according to a $t$ test. This experiment was repeated three times with similar results. $\mathbf{E}$ and $\mathbf{F}, \mathrm{H}_{2} \mathrm{O}_{2}$ accumulation at 1.5 dpa visualized by DAB staining (E) and cell-death development at $3 \mathrm{dpa}(\mathrm{F})$ in $N$. benthamiana leaves expressing LecRK-IX.1-eGFP, LecRK-IX.2-eGFP, and derivatives with P19. 
and plays a role in tolerance to lead and drought (Lee et al. 2005; Kang et al. 2010). Moreover, ABCG40 was hypothesized to function in transport of antimicrobial sclareol-like compounds to restrict pathogen growth. The compromised Phytophthora resistance of two independent Arabidopsis ABCG40 mutants that we tested in this study showed that, indeed, ABCG40 functions in resistance. However, since $A B C G 40$ mutants are not impaired in resistance to Fusarium oxysporum, Alternaria brassicicola, and Pseudomonas syringae, this ABA transporter is not a universal resistance component (Campbell et al. 2003). Although ABA import has been postulated to influence stress tolerance (Cao et al. 2013; Kang et al. 2010), the role in plant-pathogen interactions is less well defined. Depending on the nature of the interaction, ABA import can have a positive or negative effect on pathogen resistance
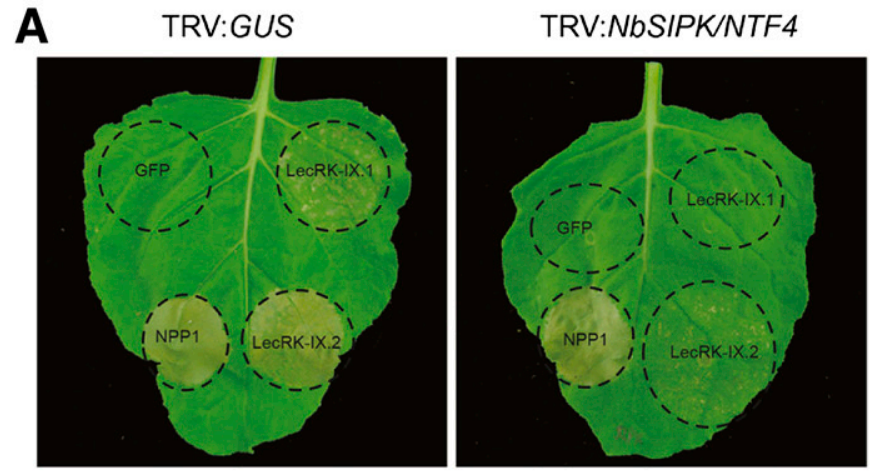

C

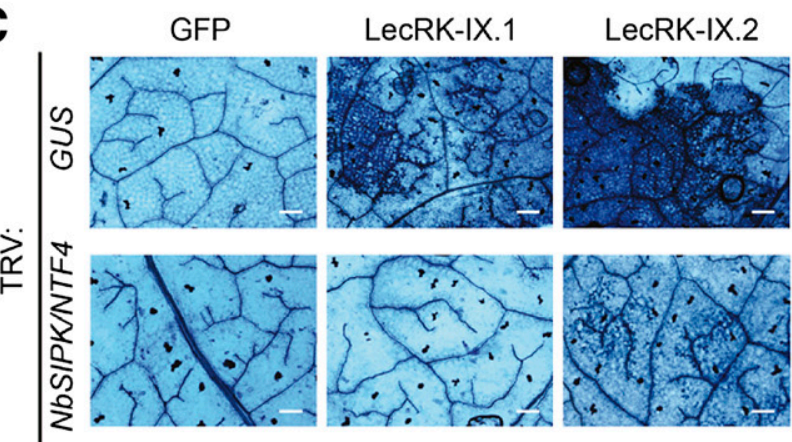

$\mathbf{E}$

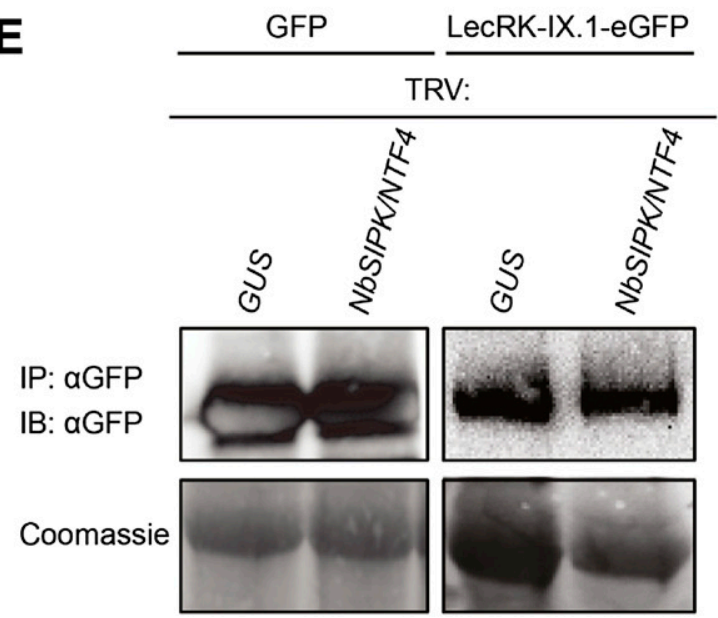

LecRK-IX.1-eGFP

TRV:
B

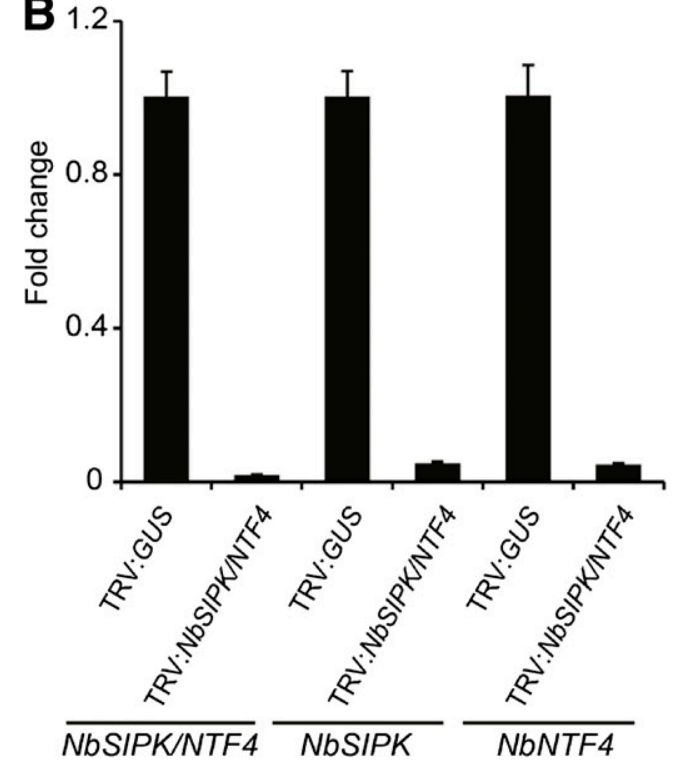

D

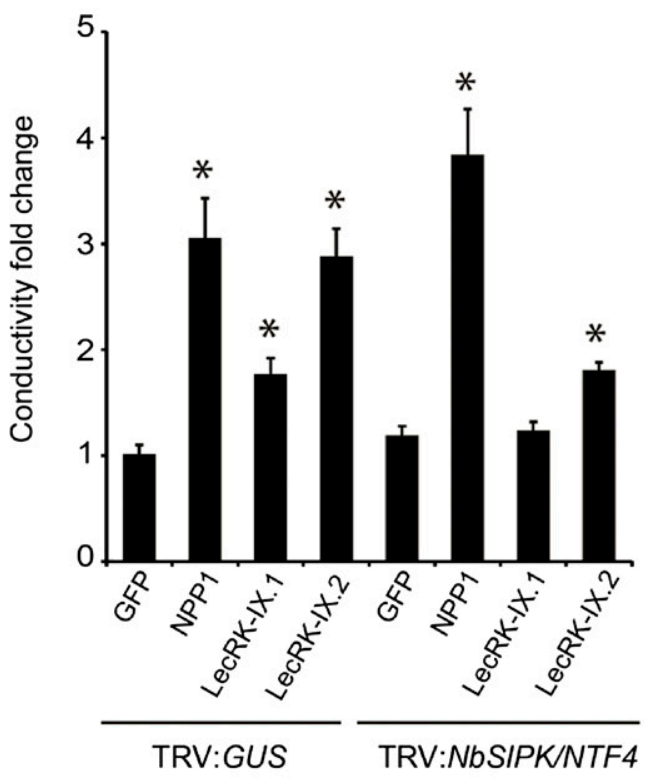

Fig. 6. Silencing of NbSIPK/NTF4 suppresses LecRK-IX.1- and LecRK-IX.2-induced cell death in Nicotiana benthamiana leaves. A, Cell death induced by LecRK-IX.1-eGFP, LecRK-IX.2-eGFP, and NPP1 on control (TRV:GUS) and NbSIPK/NTF4-silenced N. benthamiana leaves. Green fluorescent protein (GFP), NPP1, LecRK-IX.1-eGFP, and LecRK-IX.2-eGFP were expressed by Agrobacterium-mediated transient expression. Pictures were taken at 3 days after agroinfiltration (dpa). B, Relative quantification of NbSIPK and NbNTF4 transcript levels in $N$. benthamiana leaves 3 weeks after inoculation with TRV:GUS or TRV:NbSIPK/NTF4 constructs. Transcript levels were normalized using NbActin and are expressed as mean fold changes ( \pm standard deviation) relative to the transcript level in TRV:GUS-treated leaves, which was arbitrarily set as 1. C, Microscopic investigation of cell death induced by LecRK-IX.1-eGFP and LecRK-IX.2-eGFP in TRV:GUS- and TRV:NbSIPK/NTF4-treated $N$. benthamiana leaves. Leaves were collected at 3 dpa and were stained with trypan blue. Scale bars represent $200 \mu \mathrm{m}$. D, Quantification of ion leakage in TRV:GUS- or TRV:NbSIPK/NTF4-treated N. benthamiana leaves expressing GFP, NPP1, LecRK-IX.1-eGFP, or LecRK-IX.2-eGFP. Conductivity is shown as fold change relative to that in GFP-expressing leaves, which was arbitrarily set as 1. Asterisks $(*)$ indicates significant difference $(P<0.05)$, according to a $t$ test. Similar results were obtained in three independent experiments. E, Accumulation of GFP and LecRK-IX.1-eGFP in TRV:GUS- and TRV:NbSIPK/NTF4-treated N. benthamiana leaves. Total protein was immunopurified by GFP-trap_A beads and was immunodetected with anti-GFP. Coomassie staining shows the 50-kDa Rubisco band indicating the amount of protein loaded in each lane. 
(DiLeo et al. 2010; Hok et al. 2014; Ton et al. 2009). Hence, it is intriguing to figure out whether or not the Phytophthora resistance mediated by the clade IX LecRK depends on the function of ABCG40 as ABA transporter. Since ABC transporters contribute to transport of a wide variety of compounds, including ions, nucleic acids, and antimicrobial compounds (Rea 2007), binding between ABCG40 and the clade IX LecRK might influence the location of a variety of plant molecules, including $\mathrm{ABA}$, and the subsequent activation of signal transduction culminating in effective defense.

\section{MATERIALS AND METHODS}

\section{Plant material and growth conditions.}

Arabidopsis T-DNA insertion lines SALK_042414 (in this study referred to as lecrk-IX.1), SALK_111817 (lecrk-IX.2), SALK_148565.27.50 (abcg40-1), and SALK_005635.51.50 (abcg40-2) were obtained from the European Arabidopsis Stock Center NASC. Homozygosity of the T-DNA insertions was determined as previously described (Wang et al. 2014). Arabidopsis plants were grown on soil and were maintained in a conditioned growth chamber at 19 to $21^{\circ} \mathrm{C}$ with a 12 -h photoperiod and a 75 to $80 \%$ relative humidity. $N$. benthamiana plants were grown in soil in a greenhouse at 19 to $21^{\circ} \mathrm{C}$ with a 75 to $78 \%$ relative humidity and a 16-h light and 8-h dark photoperiod. Supplementary light $\left(100 \mathrm{~W} \mathrm{~m}^{-2}\right)$ was applied when the light intensity dropped below $150 \mathrm{~W} \mathrm{~m}^{-2}$.

\section{Pathogen maintenance and infection assays.}

Culturing of Phytophthora pathogens, Pseudomonas syringae pv. tomato DC3000, and Alternaria brassicicola, infection assays on Arabidopsis, and biomass measurements were performed as previously described (Wang et al. 2013a and b; Wang et al. 2014).

Infection assays on $N$. benthamiana with $P$. capsici were performed by inoculating fresh mycelial plugs $(0.5 \mathrm{~cm}$ diameter) on leaves of 6-week-old plants 1 day after agroinfiltration. Inoculated plants were kept in a climate chamber with aforementioned conditions. Disease symptoms were evaluated by measuring lesion sizes at $3 \mathrm{dpi}$, as described by Vleeshouwers et al. (1999).

\section{Gene expression analysis.}

From inoculated Arabidopsis plants, eight circular leaf discs $(0.8 \mathrm{~cm}$ diameter $)$ with the inoculation spots in the center were collected and, from noninoculated Arabidopsis plants, rosette leaves were collected. From the silenced $N$. benthamiana plants, six leaves from three individual plants were harvested and pooled. All leaf material was ground in liquid nitrogen. Total RNA isolation and qRT-PCR analysis were carried out as previously described (Wang et al. 2014). For semi-qRT-PCR, first-strand cDNA was synthesized using $1.5 \mu \mathrm{g}$ of RNA in a total volume of $25 \mu \mathrm{l}$, and the resultant cDNA was diluted 20fold. Semi-qRT-PCR was performed using $1 \mu$ l of diluted cDNA with gene-specific primers (Supplementary Table S1) in 45 cycles at $94^{\circ} \mathrm{C}$ for $30 \mathrm{~s}, 55^{\circ} \mathrm{C}$ for $30 \mathrm{~s}$, and $72^{\circ} \mathrm{C}$ for $1 \mathrm{~min}$. Actin2 was used as control and was amplified using the same PCR conditions in 28 to 30 cycles.

LecRK expression data were obtained from publicly available microarray data using the eFP-Browser at the Bio-Array Resource website (Schmid et al. 2005; Winter et al. 2007). Signal intensity $\log _{2}$ ratios of the samples relative to the mean were used as a measure for $\operatorname{LecRK}$ expression.

\section{Plasmid construction.}

The coding sequences of the full-length or truncated Arabidopsis LecRK-IX.1, LecRK-IX.2, LecRK-S.4, and ABCG40
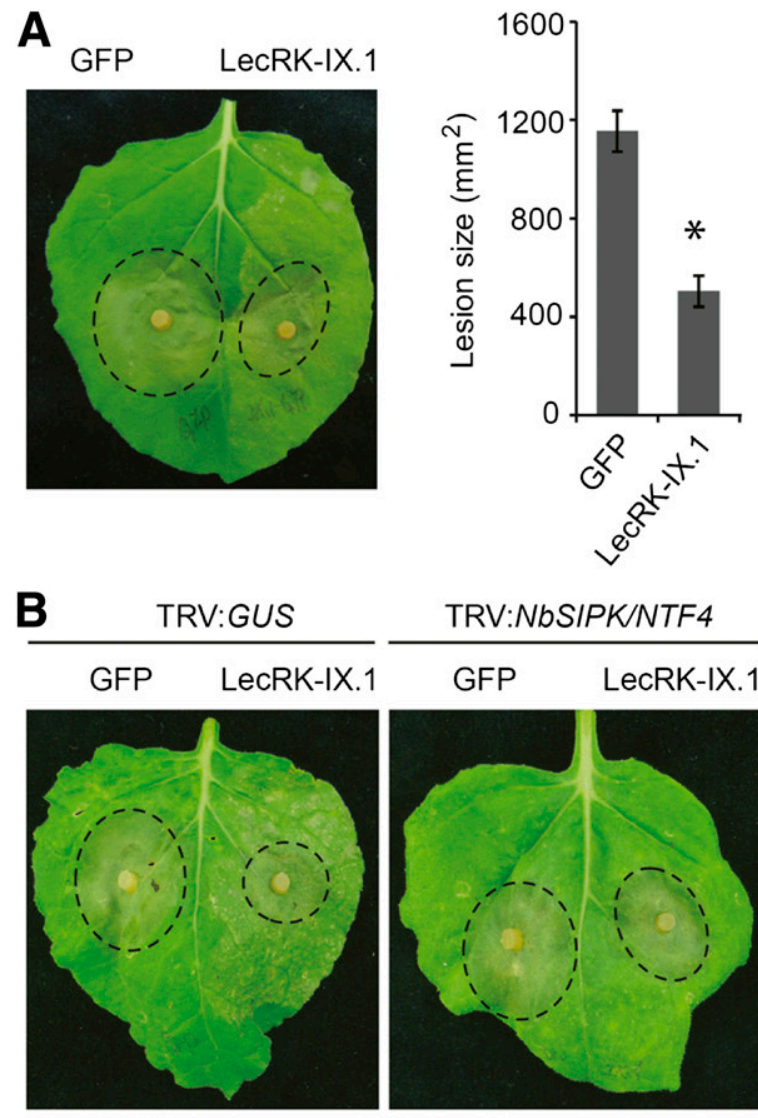

TRV:NbSIPKNNTF4
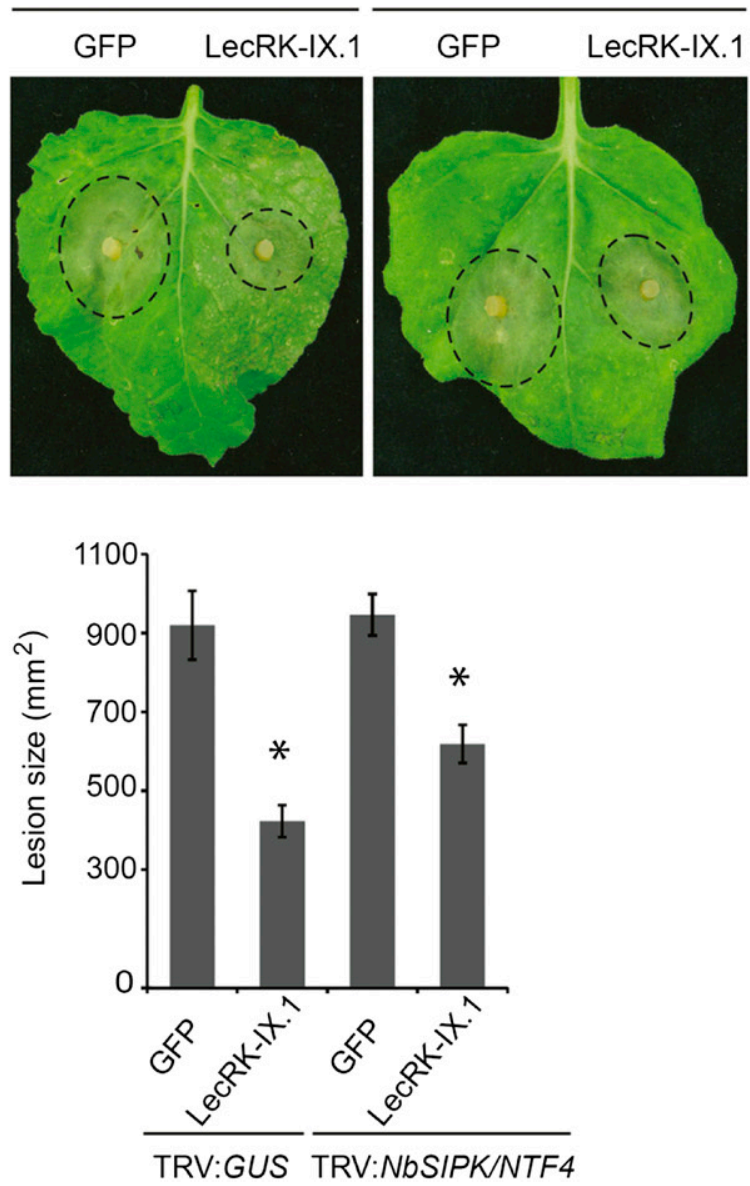

Fig. 7. Phytophthora resistance conferred by transient expression of LecRK-IX.1 in Nicotiana benthamiana. A, Disease symptoms and lesion sizes on $N$. benthamiana leaves expressing LecRK-IX.1 or green fluorescent protein (GFP) 3 days after plug-inoculation with Phytophthora capsici LT263. $P$. capsici was inoculated on $N$. benthamiana leaves $24 \mathrm{~h}$ after agroinfiltration. Each experiment includes at least 18 infiltrated $N$. benthamiana leaves. Bars represent mean lesion size ( \pm standard error $[\mathrm{SE}])$. As asterisk $(*)$ indicates significant differences in lesion sizes $(P<0.05)$, according to a $t$ test. This experiment was repeated three times with similar results. B, Disease symptoms and quantified lesion sizes on TRV:GUS- and TRV:NbSIPK/NTF4-treated $N$. benthamiana leaves expressing LecRKIX.1-eGFP or GFP upon inoculation with $P$. capsici LT263 at 3 days postinoculation. The infection assay included at least 12 infiltrated leaves per treatment. Bars represent mean lesion sizes $( \pm \mathrm{SE})$. Asterisks $(*)$ indicate significant differences in lesion size $(P<0.05)$, according to a $t$ test. This experiment was repeated three times with similar results. 
were amplified by PCR using $P f u$ DNA polymerase (Promega). Point mutations in the kinase domain were generated using overlap extension PCR. The purified PCR fragments were ligated into pENTR/D-TOPO vector (Invitrogen) and, after checking the sequences, were introduced into binary vectors pSol2095 or pGWB20, using Gateway LR
Clonase II (Invitrogen). For gene-silencing constructs, fragments were either synthesized (Eurofins MWG Operon) $(N b R b o h A / B)$ (Yoshioka et al. 2003) or were PCR-amplified (NbSIPK/NTF4) and cloned into vector pTRV-RNA2. The resulting plasmids were transformed into Agrobacterium tumefaciens GV3101.

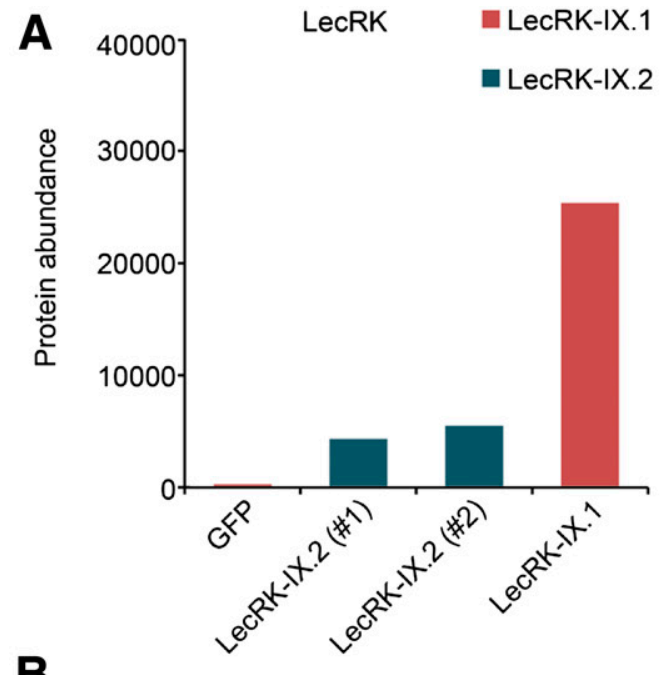

B

$>$ NbPDR1

MEPADLSNLRGRSLRASIRGSMRGSIRENSNSIWRNNGAEVFSHS ARDEDDEEALKWAALEKLPTYDRLRKGILFGSQGAAAEVDVDDLG VLERKNLLERLVKVADEDNEKFLVGIDFPSIEVRFEHLNIDADAYVG SRALPTFTNFISNFVEGLLDSIHILPSKKRQVTILKDVSGIVKPCRMTL LLGPPGSGKTTLLLALAGKLDSALKVTGKVTYNGHELHEFVPQRTA TYISQHDLHIGEMTVRETLEFSARCQGVGSRYEMLAELSRREKAAN IKPDADIDMFMKAASTEGQEAKVVTDYILKILGLDICADTMVGDQMIR GISGGQKKRVTTGEMIVGPSKALFMDEISTGLDSSTTYSIVNSLKQS VRIMKGTALISLLQPAPETYNLFDDIILLSDGYIVYEGPRDYVLEFFES MGFKCPERKGAADFLQEVTSKKDQQQYWVRRDEPYRFITSKEFAE AYQSFHVGRKVRDELATTFDKSKSHPAALTTQKYGIGKRQLLKVCT ERELLLMQRNSFVYLFKFFQLLIIALMTMTIFFRTKMPRDTAEDGGIY SGALFFVVIMIMFNGLSELPMTLYKLPVFYKQRDFLFYPSWAYAIPS WILKIPVTFAEVGMWVFLTYYVMGFDPNVGRFFKQFLLLLLVNQMA SALFRFIAAVGRTMGVASTFGAFALLLQFALGGFILARKDVKDWWI WGYWTSPLMYSVNAILVNEFDGQKWKHIVAGGTEPLGAAVVRARG FFPDAYWYWIGVGALAGFTVMFNIAYSVALAYLNPFDKPQATISDE SENNESELSPQITSTQEGDSVSENKKKGMVLPFDPHSITFDEVVYS VDMPPEMRESGTSDNRLVLLKSVSGAFRPGVLTALMGVSGAGKTT LMDVLAGRKTGGYIDGSIKISGYPKKQETFARISGYCEQNDIHSPYV TVFESLVYSAWLRLPQDVNEEKRMMFVEEVMDLVELTPLRSALVG LPGVNGLSTEQRKRLTIAVELVANPSIIFMDEPTSGLDARAAAIVMR AVRNTVDTGRTVVCTIHQPSIDIFEAFDELFLMKRGGQEIYVGPLGR QSCHLIKYFESIPGVSKIVEGYNPATWMLEVTASSQEMALGVDFTD LYKKSDLYRRNKALIDELSVPRPGTSDLHFDSEFSQPFWTQCMACL WKQHWSYWRNPAYTAVRFIFTTFIALIFGTMFWDIGTKVSRNQDLIN AMGSMYAAVLFLGVQNSSSVQPVVSVERTVFYREKAAGMYSAIPY AFAQVLIEIPYIFVQATVYGLIVYSMIGFEWTAAKFFWYFFFMFFTFL YFTFFGMMTVAVTPNQNVASIVAGFFYTVWNLFSGFIVPRPRIPIW WRWYYWGCPIAWTLYGLVASQFGDLQDPLTDQNQTVEQFLRSNF GFKHDFLGVVAAVIVAFAVVFAFTFALGIKAFNFQRR

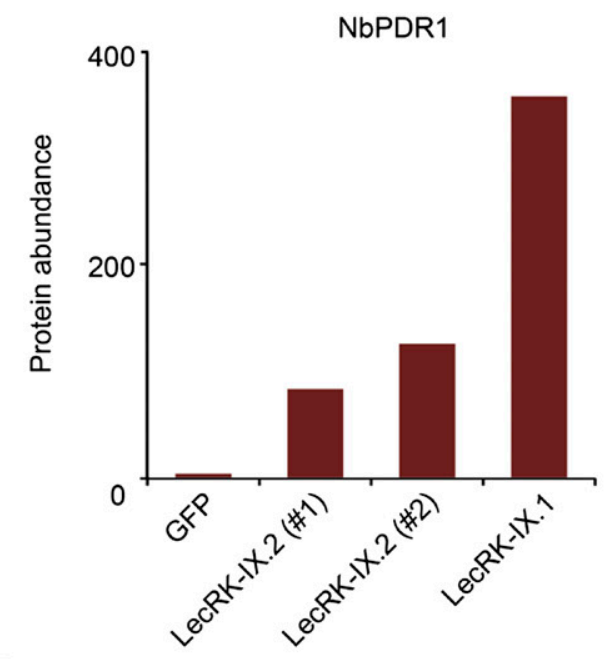

C

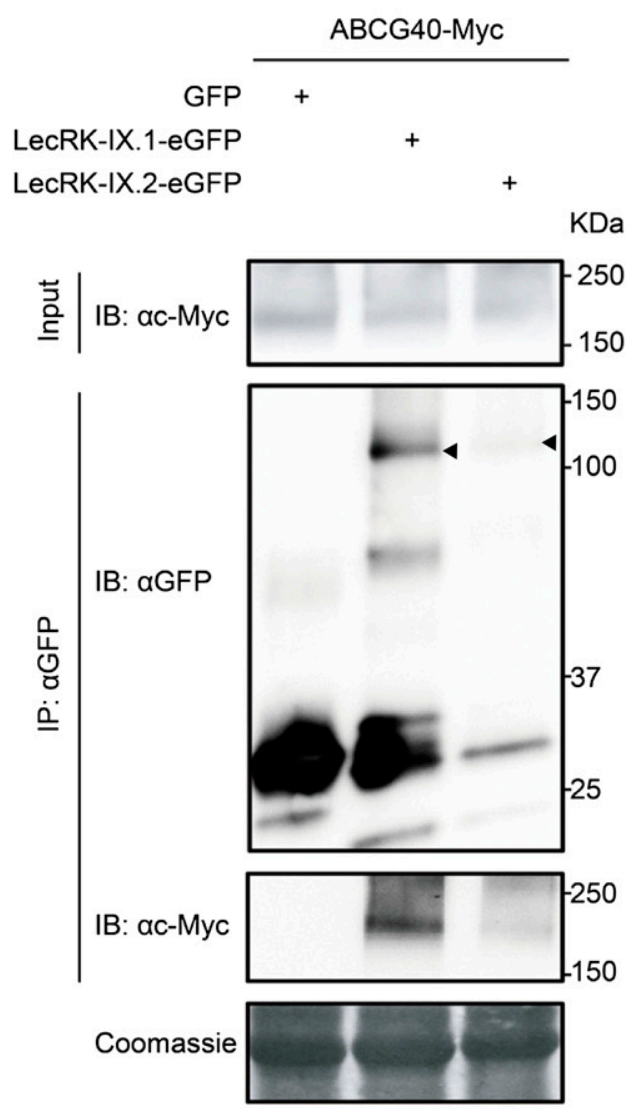

Fig. 8. NbPDR1 and ABCG40 interact with LecRK-IX.1 and LecRK-IX.2 in planta. A, Summed abundances of peptides matching to LecRK proteins (left) and the NbPDR1 protein (right), detected in liquid chromatography-data-independent acquisition $\left(\mathrm{LC}-\mathrm{MS} \mathrm{E}^{\mathrm{E}}\right.$ ) data that were generated from protein complexes immunoprecipitated with green fluorescent protein (GFP)-trap_A beads from Nicotiana benthamiana leaves expressing GFP (control), eGFP-tagged LecRKIX.1, or eGFP-tagged LecRK-IX.2 (two independent samples). The intensity of the seven most abundant peptides matching to the respective protein was summed up ( $y$ axis) as an indicator for the abundance of the LecRK or NbPDR1. B, Protein sequence of NbPDR1, with peptides detected by LC-MS ${ }^{\mathrm{E}}$ highlighted. Sequences present in peptides detected only in the LecRK-IX.1 sample are highlighted with a light shading, while those detected in both LecRKIX.1 and LecRK-IX.2 samples are highlighted with darker shading. Sequences that match uniquely to NbPDR1 are underlined. C, ABCG40 interacts with LecRK-IX.1 and LecRK-IX.2 in planta. ABCG40-Myc was coexpressed with GFP, LecRK-IX.1-eGFP, or LecRK-IX.2-eGFP in N. benthamiana. Total protein was isolated, was immunopurified by GFP-trap_A beads, and was detected with GFP or c-Myc antibodies. Black arrowheads indicate the position of eGFPtagged LecRK-IX.1 and LecRK-IX.2. Coomassie staining shows the 50-kDa Rubisco band indicating the amount of protein loaded in each lane. 
Generation of Arabidopsis transgenic lines and double mutants.

Arabidopsis plants were transformed using the floral dip method (Zhang et al. 2006). Transformed seeds were selected on 0.5 Murashige and Skoog (Duchefa) plates containing $50 \mu \mathrm{g}$ of kanamycin or $20 \mu \mathrm{g}$ of hygromycin B per milliliter. Transgene expression was detected by qRT-PCR.

Double mutants were generated by reciprocally crossing mutant lecrk-IX.1 with lecrk-IX.2. Homozygosity of the T-DNA insertion in both LecRK-IX.1 and LecRK-IX.2 in F2 progeny was confirmed by PCR-based genotyping. Expression levels of $L e c R K-I X .1$ and LecRK-IX.2 in the double mutants were analyzed by semi-qRT-PCR with Actin2 as control.

\section{A. tumefaciens-mediated transient expression} in $N$. benthamiana leaves.

A. tumefaciens strains carrying binary vectors were grown overnight at $28^{\circ} \mathrm{C}$ in yeast extract broth with appropriate antibiotics. A. tumefaciens cells were collected by centrifugation, were resuspended, and were incubated in $\mathrm{MM}$ medium (10 mM MES, $10 \mathrm{mM} \mathrm{MgCl}_{2}, \mathrm{pH}$ 5.6) with $50 \mu \mathrm{M}$ acetosyringone for $3 \mathrm{~h}$. Thereafter, cells were again collected, were resuspended in MM medium with $150 \mu \mathrm{M}$ acetosyringone, and were incubated for $1 \mathrm{~h}$.

For gene-silencing, A. tumefaciens cells carrying either pTRVRNA2 silencing constructs or pTRV1 were mixed in a ratio of $1: 1$ to a final optical density at $600 \mathrm{~nm}\left(\mathrm{OD}_{600}\right)$ of 1.0 before infiltration into cotyledons of 2-week-old $N$. benthamiana plants. For transient gene expression, $A$. tumefaciens suspensions with a final $\mathrm{OD}_{600}$ of 0.6 were syringe-infiltrated into 5 -week-old $N$. benthamiana leaves. For coinfiltration with the silencing suppressor P19, suspensions were mixed in a ratio of 1:1 to a final $\mathrm{OD}_{600}$ of 0.6 .

\section{Protein extraction, immunoprecipitation, and Western blotting.}

Leaves were collected and were ground in liquid nitrogen. Total protein was extracted by incubating ground leaf material in an extraction buffer containing $150 \mathrm{mM} \mathrm{NaCl}, 50 \mathrm{mM}$ Tris- $\mathrm{HCl}, \mathrm{pH}$ 8.0, 1.0\% IGEPAL CA-630 (Sigma), and one protease inhibitor cocktail tablet (Roche) per $50 \mathrm{ml}$ for $30 \mathrm{~min}$. Subsequently, the homogenate was centrifuged at $18,000 \mathrm{rpm}$ for $20 \mathrm{~min}$ and the supernatant was incubated with GFP-trap_A beads (Chromotek) at $4^{\circ} \mathrm{C}$ for 1 to $2 \mathrm{~h}$. The beads were then pelleted and washed with extraction buffer for six times, after which proteins were eluted

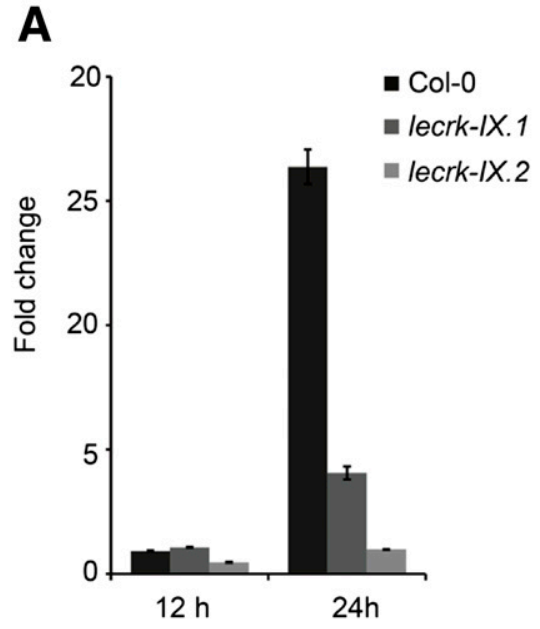

D

Col-0

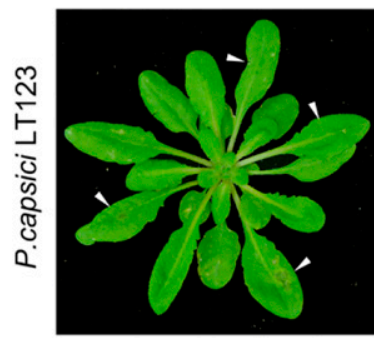

$\operatorname{abcg} 40-1$

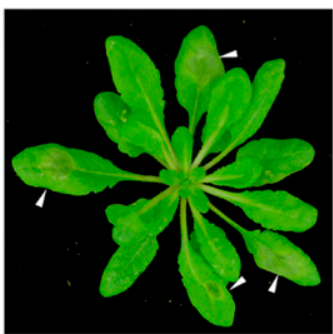

B

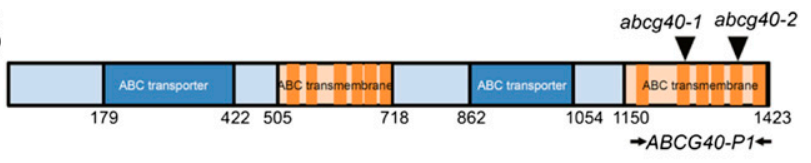

C

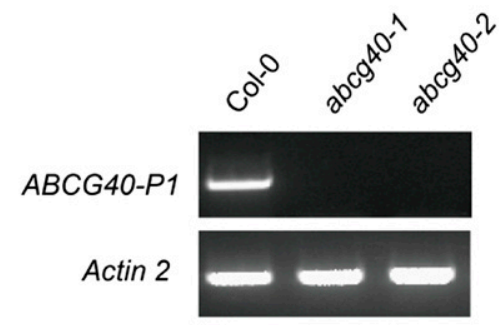

E

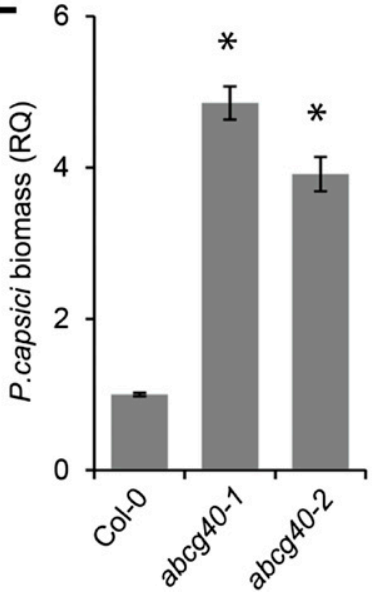

Fig. 9. Arabidopsis ABCG40 is a potential Phytophthora resistance component. A, ABCG40 expression in Col-0, lecrk-IX.1, and lecrk-IX.2 upon inoculation with P. capsici LT123. Relative transcript levels were normalized to Arabidopsis Actin2. Values are expressed as mean fold changes ( \pm standard deviation [SD]) relative to the transcript levels in mock-inoculated leaves. Experiments were repeated twice with similar results. B, Schematic representation of ABCG40. Domains were predicted by SMART. Black arrowheads point to the T-DNA insertion sites in mutants $a b c g 40-1$ and $a b c g 40-2$. ABCG40-P1 indicates the position of the primers used for semi-quantitative reverse transcription-polymerase chain reaction (qRT-PCR). C, Transcript levels of $A B C G 40$ in Col-0, $a b c g 40-1$, and $a b c g 40-2$ detected by semi-qRT-PCR. Actin2 was used as control. D, Disease symptoms on Col-0, abcg40-1, and abcg40-2 4 days after inoculation with $P$. capsici LT123. White arrowheads point to the inoculated leaves. E, Relative quantification of $P$. capsici biomass in Col-0, abcg40-1, and abcg40-2 at 4 dpi by qPCR. Each sample contains at least 12 inoculated leaves. Bars represent mean values $( \pm \mathrm{SD})$ of three technical replicates relative to that of infected Col-0 leaves, which was set as 1 . Asterisks $(*)$ indicate significantly more biomass $(P<0.05)$, according to a $t$ test. Experiments were repeated twice with similar results. 
from the beads by boiling for $5 \mathrm{~min}$. The proteins were then separated on an $8 \%$ sodium dodecyl sulfate-polyacrylamide gel electrophoresis gel or on a 4 to $20 \%$ Mini-PROTEAN TGX precast gel (Bio-Rad) and were electroblotted onto a polyvinylidene diflouride membrane (Bio-Rad). Accumulation of GFP-tagged protein was analyzed by incubating the membrane with anti-GFP-HRP (Miltenyi Biotec). For detection of Myc-tagged protein, the membrane was incubated with 1:2,000 diluted anti-c-Myc (Santa Cruz Biotechnology) and, subsequently, with 1:2,000 diluted anti-mouse Ig-HRP (Amersham). Protein $N$-glycosylation was detected using anti-HRP as described by Liebrand et al. (2012). Supersignal West Femto Chemiluminescent Substrate (Thermo Scientific) was used for signal development. Equal loading was checked by Coomassie staining.

\section{Tryptic digestion of immunopurified proteins and MS analysis.}

For MS analysis of LecRK-interacting proteins, proteins were extracted from $5 \mathrm{~g}$ of agroinfiltrated $N$. benthamiana leaves with $10 \mathrm{ml}$ of extraction buffer, and the resultant protein extract was incubated with $60 \mu \mathrm{l}$ of GFP-trap_A beads (Chromotek) at $4^{\circ} \mathrm{C}$ for $2 \mathrm{~h}$. The proteins trapped by the GFP-trap_A beads were subjected to on-bead digestion, followed by LC-MS analysis using both dataindependent acquisition (or $\mathrm{MS}^{\mathrm{E}}$ ) and data-dependent acquisition (MS/MS). For peptide separation, a nanoAcquity UPLC system (Waters Corporation) was used, employing a $2 \mathrm{G}$ nanoAcquity Trap column ( $5 \mu \mathrm{m}$; Symmetry) and a nanoAcquity UPLC HSS T3 analytical column $(75 \mu \mathrm{m} \times 15 \mathrm{~cm}, 1.8 \mu \mathrm{m})$. Water containing $0.1 \%$ formic acid was used as mobile phase A, and acetonitrile containing $0.1 \%$ formic acid was used as mobile phase B. Peptides were eluted with a gradient of 5 to $40 \%$ mobile phase B over $90 \mathrm{~min}$ at a flow rate of $300 \mathrm{nl} / \mathrm{min}$ and a column temperature of $45^{\circ} \mathrm{C}$. Eluting peptides were on-line injected into a Synapt G1 Q-TOF MS instrument (Waters Corporation), using a nanospray device coupled to the analytical column output. The Synapt MS was operated in the positive ion mode with V-Optics. For the external calibration, [Glu1] fibrinopeptide B (1 pmol/ $\mu$; Sigma) was delivered as the lock mass compound from a syringe pump to the reference sprayer of the NanoLockSpray source and sampled every $30 \mathrm{~s}$. For data-independent $\mathrm{MS}^{\mathrm{E}}$ acquisition, the collision energy was constant $4 \mathrm{eV}$ in the low collision energy MS mode, whereas the collision energy was ramped from 15 to $40 \mathrm{eV}$ during each $1.5 \mathrm{~s}$ data collection cycle in the elevated energy mode. Data-dependent MS/MS was performed by peptide fragmentation on the three most intense multiply charged ions detected in the MS survey scan $(0.6 \mathrm{~s})$ over a 300 to $1400 \mathrm{~m} / \mathrm{z}$, range and a dynamic exclusion window of $60 \mathrm{~s}$, with an automatically adjusted collision energy based on the observed precursor $\mathrm{m} / \mathrm{z}$ and charge state.

\section{Database search for protein identification.}

Continuum LC-MS/MS and $\mathrm{MS}^{\mathrm{E}}$ data were processed using ProteinLynx Global Server software (PLGS version 2.5, Waters Corporation), and the resulting list of masses containing all the fragment information was searched against a custom compiled protein sequence database containing sequences from $N$. benthamiana. Sequence information for porcine trypsin, human keratin, GFP, and the Arabidopsis receptor kinases LecRKIX. 1 and LecRK-IX. 2 were added to the database. For $\mathrm{MS}^{\mathrm{E}}$, the search was performed using the following parameters: a minimum of five fragment ions per peptide and a minimum of nine fragment ions per protein, a minimum of one peptide match per protein, and a maximum of one missed trypsin cleavage. Furthermore, cysteine carbamido-methylation and methionine oxidation were chosen as fixed and variable modifications, respectively, and a false discovery threshold of $4 \%$ was used. The false discovery rate was determined automatically in PLGS by searching the randomized database. For MS/MS analysis, the peptide tolerance was set to $30 \mathrm{ppm}$ and a fragment tolerance of $0.05 \mathrm{Da}$. The database search results were then subjected to a secondary search using the AutoMod analysis tool with a maximum of one missed trypsin cleavage and nonspecific secondary digest. The AutoMod analysis tool increases protein coverage by taking into account missed trypsin cleavages and nonspecific cleavages, posttranslational modifications, and amino acid substitutions. Finally, the MS/MS and $\mathrm{MS}^{\mathrm{E}}$ outputs were collected and merged in Excel. Protein identification was considered to be accurate when assigned based on at least two proteotypic peptides typical for proteolysis by trypsin. In the MS/MS analyses, single peptides were only kept if the ladder score was above 50.

\section{Protein quantification in Progenesis.}

Protein quantification from raw $\mathrm{MS}^{\mathrm{E}}$ data were done in Progenesis LC-MS version 4.0 (Nonlinear Dynamics) with lock-spray and dead time correction as mass calibration. Progenesis performs extraction of ion features such as mass, charge, intensity, and retention time after retention time alignment of the $\mathrm{MS}^{\mathrm{E}}$ runs from all samples. Feature intensities were normalized by the global scaling algorithm in Progenesis. Subsequently, peptide identifications from ProteinLynx were linked to matching features from Progenesis. Features matching $\mathrm{m} / \mathrm{z}$ and retention times with the identified peptides were manually checked for the detected proteins LecRKIX.1, LecRK-IX.2, and NbPDR1 and were manually corrected, if needed. The intensity of the seven most abundant peptides per protein were summed as an indicator of protein abundance.

\section{Measurement of electrolyte leakage.}

Six $N$. benthamiana leaf discs $(1.0 \mathrm{~cm}$ diameter $)$ collected 3 days after agroinfiltration were floated on $4 \mathrm{ml}$ of deionized water for $2 \mathrm{~h}$ under continuous shaking (200 rpm) at room temperature. Conductivity was measured using a Mettler Toledo InLab741 ISM conductivity meter (Mettler Toledo). Three biological repeats were performed, each with six replicates.

\section{Trypan blue and DAB staining.}

Trypan blue staining was performed as previously described (Wang et al. 2011). For DAB staining, leaves were immersed into DAB solution (1 mg of DAB-HCl per milliliter, $\mathrm{pH} \mathrm{3.7)} \mathrm{for} 8 \mathrm{~h}$. Leaves were subsequently washed with distilled $\mathrm{H}_{2} \mathrm{O}$ to remove the staining solution and were destained with $96 \%$ ethanol. Experiments were repeated three times each, with at least six leaves from three independent plants.

\section{ACKNOWLEDGMENTS}

We thank H. Meijer for discussion and critically reading the manuscript, P. Smit and D. Sueldo for providing the pSol2095 vector and the GFP construct, H. Smid and B. Essenstam from Unifarm for taking care of the plants and H. Juhar for assistance. This research was supported by a Wageningen University sandwich-Ph.D. fellowship and a Huygens scholarship (Y. Wang), a VENI grant (K. Bouwmeester) from the Netherlands Organization for Scientific Research (Technology Foundation NWO-STW), a CBSG2012/NPC2 proteomics hotel project, and the Food-for-Thought campaign of the Wageningen University Fund.

\section{LITERATURE CITED}

Asai, S., Ohta, K., and Yoshioka, H. 2008. MAPK signaling regulates nitric oxide and NADPH oxidase-dependent oxidative bursts in Nicotiana benthamiana. Plant Cell 20:1390-1406.

Attard, A., Gourgues, M., Callemeyn-Torre, N., and Keller, H. 2010. The immediate activation of defense responses in Arabidopsis roots is not sufficient to prevent Phytophthora parasitica infection. New Phytol. 187:449-460

Boller, T., and Felix, G. 2009. A renaissance of elicitors: perception of microbe-associated molecular patterns and danger signals by patternrecognition receptors. Annu. Rev. Plant Biol. 60:379-406. 
Bouwmeester, K., de Sain, M., Weide, R., Gouget, A., Klamer, S., Canut, H., and Govers, F. 2011. The lectin receptor kinase LecRK-I.9 is a novel Phytophthora resistance component and a potential host target for a RXLR effector. PLoS Pathog. 7:e1001327.

Bouwmeester, K., and Govers, F. 2009. Arabidopsis L-type lectin receptor kinases: Phylogeny, classification, and expression profiles. J. Exp. Bot. 60:4383-4396.

Bultreys, A., Trombik, T., Drozak, A., and Boutry, M. 2009. Nicotiana plumbaginifolia plants silenced for the ATP-binding cassette transporter gene NpPDR1 show increased susceptibility to a group of fungal and oomycete pathogens. Mol. Plant Pathol. 10:651-663.

Campbell, E. J., Schenk, P. M., Kazan, K., Penninckx, I. A. M. A., Anderson, J. P., Maclean, D. J., Cammue, B. P. A., Ebert, P. R., and Manners, J. M. 2003. Pathogen-responsive expression of a putative ATPbinding cassette transporter gene conferring resistance to the diterpenoid sclareol is regulated by multiple defense signaling pathways in Arabidopsis. Plant Physiol. 133:1272-1284.

Cao, M., Liu, X., Zhang, Y., Xue, X., Zhou, X. E., Melcher, K., Gao, P., Wang, F., Zeng, L., Zhao, Y., Zhao, Y., Deng, P., Zhong, D., Zhu, J. K., Xu, H. E., and $\mathrm{Xu}, \mathrm{Y}$. 2013. An ABA-mimicking ligand that reduces water loss and promotes drought resistance in plants. Cell Res. 23:1043-1054

Chinchilla, D., Shan, L., He, P., de Vries, S., and Kemmerling, B. 2009. One for all: The receptor-associated kinase BAK1. Trends Plant Sci. 14: 535-541.

Choi, J., Tanaka, K., Cao, Y., Qi, Y., Qiu, J., Liang, Y., Lee, S. Y., and Stacey, G. 2014. Identification of a plant receptor for extracellular ATP. Science 343:290-294.

Coll, N. S., Epple, P., and Dangl, J. L. 2011. Programmed cell death in the plant immune system. Cell Death Differ. 18:1247-1256.

Desclos-Theveniau, M., Arnaud, D., Huang, T.-Y., Lin, G. J.-C., Chen, W.-Y., Lin, Y.-C., and Zimmerli, L. 2012. The Arabidopsis lectin receptor kinase LecRK-V.5 represses stomatal immunity induced by Pseudomonas syringae pv. tomato DC3000. PLoS Pathog. 8:e1002513.

Dickman, M. B., and de Figueiredo, P. 2013. Death be not proud-Cell death control in plant fungal interactions. PLoS Pathog. 9:e1003542.

Dickman, M. B., and Fluhr, R. 2013. Centrality of host cell death in plantmicrobe interactions. Annu. Rev. Phytopathol. 51:543-570.

DiLeo, M. V., Pye, M. F., Roubtsova, T. V., Duniway, J. M., Macdonald, J. D., Rizzo, D. M., and Bostock, R. M. 2010. Abscisic acid in salt stress predisposition to Phytophthora root and crown rot in tomato and chrysanthemum. Phytopathology 100:871-879.

Gabriëls, S. H. E. J., Takken, F. L. W., Vossen, J. H., de Jong, C. F., Liu, Q., Turk, S. C. H. J., Wachowski, L. K., Peters, J., Witsenboer, H. M. A., de Wit, P. J. G. M., and Joosten, M. H. A. J. 2006. CDNA-AFLP combined with functional analysis reveals novel genes involved in the hypersensitive response. Mol. Plant Microbe Interact. 19:567-576.

Gabriëls, S. H. E. J., Vossen, J. H., Ekengren, S. K., van Ooijen, G., AbdEl-Haliem, A. M., van den Berg, G. C., Rainey, D. Y., Martin, G. B., Takken, F. L. W., de Wit, P. J. G. M., and Joosten, M. H. A. J. 2007. An NB-LRR protein required for HR signalling mediated by both extra- and intracellular resistance proteins. Plant J. 50:14-28.

Gao, M., Wang, X., Wang, D., Xu, F., Ding, X., Zhang, Z., Bi, D., Cheng, Y. T., Chen, S., Li, X., and Zhang, Y. 2009. Regulation of cell death and innate immunity by two receptor-like kinases in Arabidopsis. Cell Host Microbe 6:34-44

Genger, R. K., Jurkowski, G. I., McDowell, J. M., Lu, H., Jung, H. W., Greenberg, J. T., and Bent, A. F. 2008. Signaling pathways that regulate the enhanced disease resistance of Arabidopsis "defense, no death" mutants. Mol. Plant Microbe Interact. 21:1285-1296.

Gómez-Gómez, L., Bauer, Z., and Boller, T. 2001. Both the extracellular leucine-rich repeat domain and the kinase activity of FSL2 are required for flagellin binding and signaling in Arabidopsis. Plant Cell 13: 1155-1163.

Gouget, A., Senchou, V., Govers, F., Sanson, A., Barre, A., Rougé, P., PontLezica, R., and Canut, H. 2006. Lectin receptor kinases participate in protein-protein interactions to mediate plasma membrane-cell wall adhesions in Arabidopsis. Plant Physiol. 140:81-90.

Häweker, H., Rips, S., Koiwa, H., Salomon, S., Saijo, Y., Chinchilla, D., Robatzek, S., and von Schaewen, A. 2010. Pattern recognition receptors require $N$-glycosylation to mediate plant immunity. J. Biol. Chem. 285: 4629-4636.

Hervé, C., Serres, J., Dabos, P., Canut, H., Barre, A., Rougé, P., and Lescure, B. 1999. Characterization of the Arabidopsis lecRK-a genes: Members of a superfamily encoding putative receptors with an extracellular domain homologous to legume lectins. Plant Mol. Biol. 39:671-682.

Hok, S., Allasia, V., Andrio, E., Naessens, E., Ribes, E., Panabières, F., Attard, A., Ris, N., Clément, M., Barlet, X., Marco, Y., Grill, E.,
Eichmann, R., Weis, C., Hückelhoven, R., Ammon, A., Ludwig-Müller, J., Voll, L. M., and Keller, H. 2014. The receptor kinase IMPAIRED OOMYCETE SUSCEPTIBILITY1 attenuates abscisic acid responses in Arabidopsis. Plant Physiol. 166:1506-1518.

Huang, P. Y., Yeh, Y. H., Liu, A. C., Cheng, C. P., and Zimmerli, L. 2014. The Arabidopsis LecRK-VI.2 associates with the pattern-recognition receptor FLS2 and primes Nicotiana benthamiana pattern-triggered immunity. Plant J. 79:243-255.

Huitema, E., Vleeshouwers, V. G. A. A., Francis, D. M., and Kamoun, S. 2003. Active defence responses associated with non-host resistance of Arabidopsis thaliana to the oomycete pathogen Phytophthora infestans. Mol. Plant Pathol. 4:487-500.

Kang, J., Hwang, J. U., Lee, M., Kim, Y. Y., Assmann, S. M., Martinoia, E., and Lee, Y. 2010. PDR-type ABC transporter mediates cellular uptake of the phytohormone abscisic acid. Proc. Natl. Acad. Sci. U.S.A. 107: 2355-2360

Kornev, A. P., Haste, N. M., Taylor, S. S., and Eyck, L. F. 2006. Surface comparison of active and inactive protein kinases identifies a conserved activation mechanism. Proc. Natl. Acad. Sci. U.S.A. 103 $17783-17788$

Lee, M., Lee, K., Lee, J., Noh, E. W., and Lee, Y. 2005. AtPDR12 contributes to lead resistance in Arabidopsis. Plant Physiol. 138:827-836.

Li, C. H., Wang, G., Zhao, J. L., Zhang, L. Q., Ai, L. F., Han, Y. F., Sun, D. Y., Zhang, S. W., and Sun, Y. 2014. The receptor-like kinase SIT1 mediates salt sensitivity by activating MAPK3/6 and regulating ethylene homeostasis in rice. Plant Cell 26:2538-2553.

Liebrand, T. W. H., Smit, P., Abd-El-Haliem, A., de Jonge, R., Cordewener, J. H. G., America, A. H. P., Sklenar, J., Jones, A. M. E., Robatzek, S., Thomma, B. P. H. J., Tameling, W. I. L., and Joosten, M. H. A. J. 2012. Endoplasmic reticulum-quality control chaperones facilitate the biogenesis of $\mathrm{Cf}$ receptor-like proteins involved in pathogen resistance of tomato. Plant Physiol. 159:1819-1833.

Liebrand, T. W. H., van den Berg, G. C. M., Zhang, Z., Smit, P., Cordewener, J. H. G., America, A. H. P., Sklenar, J., Jones, A. M. E., Tameling, W. I. L., Robatzek, S., Thomma, B. P. H. J., and Joosten, M. H. A. J. 2013. Receptor-like kinase SOBIR1/EVR interacts with receptor-like proteins in plant immunity against fungal infection. Proc. Natl. Acad. Sci. U.S.A. 110:10010-10015.

Liebrand, T. W. H., van den Burg, H. A., and Joosten, M. H. A. J. 2014. Two for all: Receptor-associated kinases SOBIR1 and BAK1. Trends Plant Sci. 19:123-132.

Macho, A. P., and Zipfel, C. 2014. Plant PRRs and the activation of innate immune signaling. Mol. Cell 54:263-272.

Meng, X., and Zhang, S. 2013. MAPK cascades in plant disease resistance signaling. Annu. Rev. Phytopathol. 51:245-266.

Morillo, S. A., and Tax, F. E. 2006. Functional analysis of receptor-like kinases in monocots and dicots. Curr. Opin. Plant Biol. 9:460-469.

Mur, L. A., Kenton, P., Lloyd, A. J., Ougham, H., and Prats, E. 2008. The hypersensitive response; the centenary is upon us but how much do we know? J. Exp. Bot. 59:501-520.

Noh, Y. S., and Amasino, R. M. 1999. Identification of a promoter region responsible for the senescence-specific expression of SAG12. Plant Mol. Biol. 41:181-194.

Nolen, B., Taylor, S., and Ghosh, G. 2004. Regulation of protein kinases; controlling activity through activation segment conformation. Mol. Cell 15:661-675.

Pontier, D., Gan, S., Amasino, R. M., Roby, D., and Lam, E. 1999. Markers for hypersensitive response and senescence show distinct patterns of expression. Plant Mol. Biol. 39:1243-1255.

Rea, P. A. 2007. Plant ATP-binding cassette transporters. Annu. Rev. Plant Biol. 58:347-375.

Ren, D., Yang, K. Y., Li, G. J., Liu, Y., and Zhang, S. 2006. Activation of $\mathrm{Ntf} 4$, a tobacco mitogen-activated protein kinase, during plant defense response and its involvement in hypersensitive response-like cell death. Plant Physiol. 141:1482-1493.

Roetschi, A., Si-Ammour, A., Belbahri, L., Mauch, F., and Mauch-Mani, B. 2001. Characterization of an Arabidopsis-Phytophthora pathosystem: Resistance requires a functional PAD2 gene and is independent of salicylic acid, ethylene and jasmonic acid signalling. Plant J. 28: 293-305.

Rustérucci, C., Aviv, D. H., Holt, B. F., 3rd, Dangl, J. L., and Parker, J. E. 2001. The disease resistance signaling components EDS1 and PAD4 are essential regulators of the cell death pathway controlled by LSD1 in Arabidopsis. Plant Cell 13:2211-2224.

Schlaeppi, K., Abou-Mansour, E., Buchala, A., and Mauch, F. 2010. Disease resistance of Arabidopsis to Phytophthora brassicae is established by the sequential action of indole glucosinolates and camalexin. Plant J. 62:840-851. 
Schmid, M., Davison, T. S., Henz, S. R., Pape, U. J., Demar, M., Vingron, M., Schölkopf, B., Weigel, D., and Lohmann, J. U. 2005. A gene expression map of Arabidopsis thaliana development. Nat. Genet. 37:501-506.

Schwessinger, B., and Ronald, P. C. 2012. Plant innate immunity: Perception of conserved microbial signatures. Annu. Rev. Plant Biol. 63:451-482.

Schwessinger, B., Roux, M., Kadota, Y., Ntoukakis, V., Sklenar, J., Jones, A., and Zipfel, C. 2011. Phosphorylation-dependent differential regulation of plant growth, cell death, and innate immunity by the regulatory receptor-like kinase BAK1. PLoS Genet. 7:e1002046.

Segonzac, C., Feike, D., Gimenez-Ibanez, S., Hann, D. R., Zipfel, C., and Rathjen, J. P. 2011. Hierarchy and roles of pathogen-associated molecular pattern-induced responses in Nicotiana benthamiana. Plant Physiol. 156:687-699.

Seo, S., Gomi, K., Kaku, H., Abe, H., Seto, H., Nakatsu, S., Neya, M., Kobayashi, M., Nakaho, K., Ichinose, Y., Mitsuhara, I., and Ohashi, Y. 2012. Identification of natural diterpenes that inhibit bacterial wilt disease in tobacco, tomato and Arabidopsis. Plant Cell Physiol. 53:1432-1444.

Shiu, S. H., and Bleecker, A. B. 2001. Plant receptor-like kinase gene family: Diversity, function, and signaling. Sci. STKE 2001:re22.

Singh, P., Chien, C. C., Mishra, S., Tsai, C. H., and Zimmerli, L. 2013. The Arabidopsis LECTIN RECEPTOR KINASE-VI.2 is a functional protein kinase and is dispensable for basal resistance to Botrytis cinerea. Plant Signal. Behav. 8:e22611.

Singh, P., Kuo, Y. C., Mishra, S., Tsai, C. H., Chien, C. C., Chen, C. W., Desclos-Theveniau, M., Chu, P. W., Schulze, B., Chinchilla, D., Boller, T., and Zimmerli, L. 2012. The lectin receptor kinase-VI.2 is required for priming and positively regulates Arabidopsis pattern-triggered immunity. Plant Cell 24:1256-1270.

Spoel, S. H., and Dong, X. 2012. How do plants achieve immunity? Defence without specialized immune cells. Nat. Rev. Immunol. 12:89-100.

Strasser, R., Bondili, J. S., Vavra, U., Schoberer, J., Svoboda, B., Glössl, J., Léonard, R., Stadlmann, J., Altmann, F., Steinkellner, H., and Mach, L. 2007. A unique $\beta 1,3$-galactosyltransferase is indispensable for the biosynthesis of $\mathrm{N}$-glycans containing Lewis a structures in Arabidopsis thaliana. Plant Cell 19:2278-2292.

Stukkens, Y., Bultreys, A., Grec, S., Trombik, T., Vanham, D., and Boutry, M. 2005. NpPDR1, a pleiotropic drug resistance-type ATP-binding cassette transporter from Nicotiana plumbaginifolia, plays a major role in plant pathogen defense. Plant Physiol. 139:341-352.

Sun, W., Cao, Y., Jansen Labby, K., Bittel, P., Boller, T., and Bent, A. F. 2012. Probing the Arabidopsis flagellin receptor: FLS2-FLS2 association and the contributions of specific domains to signaling function. Plant Cell 24:1096-1113.

Sun, Y., Li, L., Macho, A. P., Han, Z., Hu, Z., Zipfel, C., Zhou, J. M., and Chai, J. 2013. Structural basis for flg22-induced activation of the Arabidopsis FLS2-BAK1 immune complex. Science 342:624-628.

Takahashi, H., Kai, A., Yamashita, M., Ando, S., Sekine, K. T., Kanayama, Y., and Tomita, H. 2012. Cyclic nucleotide-gated ion channel-mediated cell death may not be critical for $R$ gene-conferred resistance to Cucumber mosaic virus in Arabidopsis thaliana. Physiol. Mol. Plant Pathol. 79:40-48.

Takahashi, Y., Nasir, K. H., Ito, A., Kanzaki, H., Matsumura, H., Saitoh, H., Fujisawa, S., Kamoun, S., and Terauchi, R. 2007. A high-throughput screen of cell-death-inducing factors in Nicotiana benthamiana identifies a novel MAPKK that mediates INF1-induced cell death signaling and non-host resistance to Pseudomonas cichorii. Plant J. 49:1030-1040.

Ton, J., Flors, V., and Mauch-Mani, B. 2009. The multifaceted role of ABA in disease resistance. Trends Plant Sci. 14:310-317.
Vaid, N., Macovei, A., and Tuteja, N. 2013. Knights in action: Lectin receptor-like kinases in plant development and stress responses. Mol. Plant 6:1405-1418.

Van Breusegem, F., and Dat, J. F. 2006. Reactive oxygen species in plant cell death. Plant Physiol. 141:384-390.

van Damme, M., Bozkurt, T. O., Cakir, C., Schornack, S., Sklenar, J., Jones, A. M. E., and Kamoun, S. 2012. The Irish potato famine pathogen Phytophthora infestans translocates the CRN8 kinase into host plant cells. PLoS Pathog. 8:e1002875.

van den Brûle, S., and Smart, C. C. 2002. The plant PDR family of ABC transporters. Planta 216:95-106.

Vleeshouwers, V. G. A. A., van Dooijeweert, W., Keizer, L. C. P., Sijpkes, L., Govers, F., and Colon, L. T. 1999. A laboratory assay for Phytophthora infestans resistance in various Solanum species reflects the field situation. Eur. J. Plant Pathol. 105:241-250.

Wang, Y., Bouwmeester, K., Beseh, P., Shan, W., and Govers, F. 2014. Phenotypic analyses of Arabidopsis T-DNA insertion lines and expression profiling reveal that multiple L-type lectin receptor kinases are involved in plant immunity. Mol. Plant Microbe Interact. 27: 1390-1402.

Wang, Y., Bouwmeester, K., van de Mortel, J. E., Shan, W., and Govers, F. 2013a. A novel Arabidopsis-oomycete pathosystem: Differential interactions with Phytophthora capsici reveal a role for camalexin, indole glucosinolates and salicylic acid in defence. Plant Cell Environ. 36: 1192-1203.

Wang, Y., Bouwmeester, K., van de Mortel, J. E., Shan, W., and Govers, F. 2013b. Induced expression of defense-related genes in Arabidopsis upon infection with Phytophthora capsici. Plant Signal. Behav. 8:e24618.

Wang, Y., Meng, Y., Zhang, M., Tong, X., Wang, Q., Sun, Y., Quan, J., Govers, F., and Shan, W. 2011. Infection of Arabidopsis thaliana by Phytophthora parasitica and identification of variation in host specificity. Mol. Plant Pathol. 12:187-201.

Winter, D., Vinegar, B., Nahal, H., Ammar, R., Wilson, G. V., and Provart, N. J. 2007. An "electronic fluorescent pictograph" browser for exploring and analyzing large-scale biological data sets. PLoS ONE 2:e718.

Yoshioka, H., Numata, N., Nakajima, K., Katou, S., Kawakita, K., Rowland, O., Jones, J. D. G., and Doke, N. 2003. Nicotiana benthamiana gp91 ${ }^{\text {phox }}$ homologs $N b r b o h A$ and $N b r b o h B$ participate in $\mathrm{H}_{2} \mathrm{O}_{2}$ accumulation and resistance to Phytophthora infestans. Plant Cell 15:706-718.

Yu, I. C., Parker, J., and Bent, A. F. 1998. Gene-for-gene disease resistance without the hypersensitive response in Arabidopsis dnd1 mutant. Proc. Natl. Acad. Sci. U.S.A. 95:7819-7824.

Zhang, J., and Zhou, J. M. 2010. Plant immunity triggered by microbial molecular signatures. Mol. Plant 3:783-793.

Zhang, S., and Liu, Y. 2001. Activation of salicylic acid-induced protein kinase, a mitogen-activated protein kinase, induces multiple defense responses in tobacco. Plant Cell 13:1877-1889.

Zhang, X., Henriques, R., Lin, S. S., Niu, Q. W., and Chua, N. H. 2006. Agrobacterium-mediated transformation of Arabidopsis thaliana using the floral dip method. Nat. Protoc. 1:641-646.

Zhou, C., Cai, Z., Guo, Y., and Gan, S. 2009. An Arabidopsis mitogenactivated protein kinase cascade, MKK9-MPK6, plays a role in leaf senescence. Plant Physiol. 150:167-177.

\section{AUTHOR-RECOMMENDED INTERNET RESOURCES}

Bio-Array Resource website: http://www.bar.utoronto.ca NASC, the European Arabidopsis Stock Center: http://arabidopsis.info 